\title{
An Integrated Model for Asphaltene Deposition in Wellbores/Pipelines above Bubble Pressures
}

Q. Guan ${ }^{1}$, A. Goharzadeh ${ }^{1}$, J.C. Chai ${ }^{2}$, F.M. Vargas ${ }^{3}$, S.L. Biswal ${ }^{3}$, W.G. Chapman ${ }^{3}$, M. Zhang ${ }^{4}$ and Y.F. Yap ${ }^{1, *}$

${ }^{1}$ Department of Mechanical Engineering, Khalifa University of Science and Technology, Sas Al Nakheel Campus, Abu Dhabi, UAE

${ }^{2}$ Department of Engineering and Technology, University of Huddersfield, Huddersfield, UK ${ }^{3}$ Department of Chemical and Biomolecular Engineering, Rice University, Houston, USA ${ }^{4}$ School of Energy and Power Engineering, Nanjing University of Science and Technology, Nanjing, P.R. China.

${ }^{*}$ Corresponding author:

Tel: +97126075175

Fax: +97126075200

Email address: yfatt@pi.ac.ae

Address: Department of Mechanical Engineering,

Khalifa University of Science and Technology,

Sas Al Nakheel Campus, P.O. Box 2533, Abu Dhabi, UAE 
Key Words: asphaltene deposition, integrated transport and thermodynamic models, evolving deposit layer

\section{Nomenclature}

$\begin{array}{ll}A & \text { wellbore/pipeline cross-sectional area }\left(\mathrm{m}^{2}\right) \\ A_{f} & \text { flow channel cross-sectional area }\left(\mathrm{m}^{2}\right) \\ C_{d i s} & \text { dissolved asphaltene concentration }\left(\mathrm{kg} / \mathrm{m}^{3}\right) \\ C_{e q} & \text { equilibrium asphaltene concentration }\left(\mathrm{kg} / \mathrm{m}^{3}\right) \\ C_{p r e} & \text { precipitated asphaltene concentration } \\ C_{p} & \text { specific heat }(\mathrm{J} / \mathrm{kg} \cdot \mathrm{K}) \\ D & \text { wellbore/pipeline diameter }(\mathrm{m}) \\ f & \text { fanning friction factor } \\ f_{w} & \text { volumetric viscous force }\left(\mathrm{N} / \mathrm{m}^{3}\right) \\ g & \text { acceleration of gravity }\left(\mathrm{kg} \cdot \mathrm{m} / \mathrm{s}^{2}\right) \\ k & \text { kinetic coefficient }(\mathrm{s}-1) \\ k_{i j} & \text { binary interaction parameter } \\ L & \text { wellbore/pipeline length (m) } \\ L_{1} & \text { asphaltene-lean liquid phase } \\ L_{2} & \text { asphaltene-rich liquid phase } \\ M W & \text { molecular weight (kg/mol) } \\ m & \text { order of kinetic reaction } \\ N & \text { number of control volumes } \\ N_{c} & \text { number of components in crude oil } \\ p & \text { pressure (Pa) } \\ R & \text { wellbore/pipeline radius (m) } \\ R e & \text { Reynolds number }\end{array}$




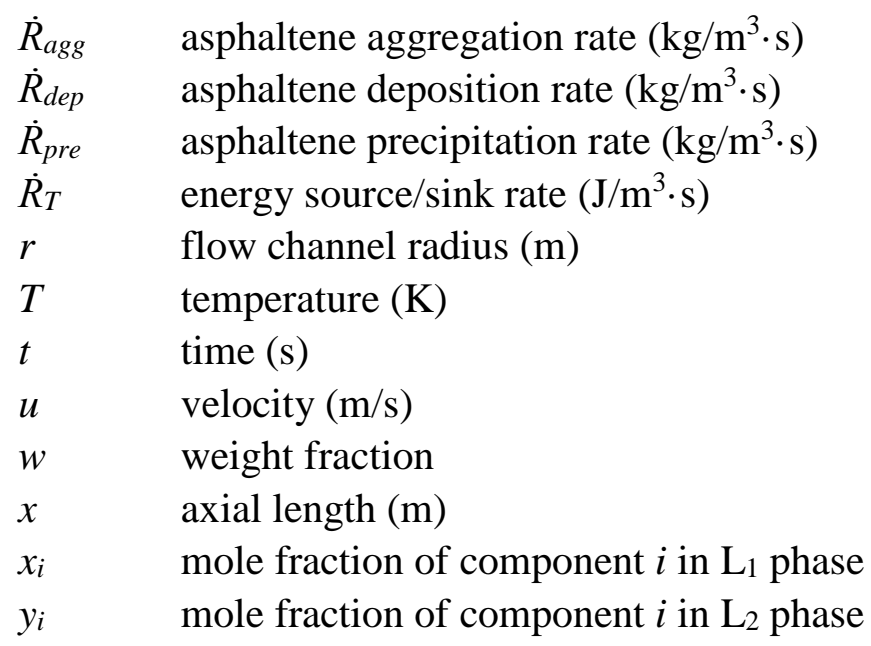

\section{Greek Symbols}

$\begin{array}{ll}\alpha & \text { Crude oil volume fraction } \\ \beta & \text { Mole fraction of a possible phase } \\ \delta & \text { Deposit layer thickness }(\mathrm{m}) \\ \varepsilon & \text { Surface roughness }(\mathrm{m}) \\ \mu & \text { Crude oil dynamic viscosity }(\mathrm{Pa} \cdot \mathrm{s}) \\ \rho & \text { Crude oil density }\left(\mathrm{kg} / \mathrm{m}^{3}\right) \\ \rho_{\text {dep }} & \text { Deposit density }\left(\mathrm{kg} / \mathrm{m}^{3}\right) \\ \tau & \text { Local shear stress }\left(\mathrm{N} / \mathrm{m}^{2}\right) \\ v & \text { Molar volume }\left(\mathrm{m}^{3} / \mathrm{mol}\right)\end{array}$

\section{Subscripts}

agg asphaltene aggregation

asph asphaltene component

dep asphaltene deposition

dis asphaltene re-dissolution

i downstream interface

i-1 upstream interface

in inlet

liquid total liquid phase

pre asphaltene precipitation

1 asphaltene-lean liquid phase

2 asphaltene-rich liquid phase

\section{Superscripts}

$n \quad$ current time step

$n-1 \quad$ previous time step 


\section{Introduction}

Asphaltene has been recognized as the cholesterol of petroleum for decades due to its precipitation and deposition in oil production, transportation and processing facilities, causing tremendous losses to the oil industry each year (Akbarzadeh et al., 2007; Kokal and Sayegh, 1995). When oil flows up along wellbores, both temperature $(T)$ and pressure $(p)$ change accordingly. Besides, the composition of oil $\left(x_{i}\right)$ also alters due to oil-based mud contamination, comingling of different streams and injection of gas or solvent. Altogether, these three changes (i.e. $T, p$ and $x_{i}$ ) affect the stability of asphaltene leading to asphaltene precipitation which produces small particles in oil. After transported to the near-wall region by diffusion, these particles could potentially attach to the wall or the deposit front forming an immobile solid-like layer. As a consequence, the flow passage gets blocked, the pressure drop is increased, and hence, oil production is effectively impaired. Vast expenditure including both treatment cost and daily production loss is devoted to various preventive and remedial measures (Creek, 2005). In this respect, accurate prediction of asphaltene deposition is imperative for petroleum industry to forecast the associated production problems.

Asphaltene precipitation is a necessary but not sufficient condition for asphaltene deposition (Akbarzadeh et al., 2011). Precipitation modeling for (1) crude oil during primary depletion (Kord and Ayatollahi, 2012; Nakhli et al., 2011; Nghiem and Coombe, 1997), (2) crude oil with miscible gas flooding (Arya et al., 2015; Gonzalez et al., 2005; Gonzalez et al., 2008), and (3) n-alkane diluted heavy oils and bitumen (Akbarzadeh et al., 2005; Alboudwarej et al., 2003; Li and Firoozabadi, 2010) were performed using solid models (Nghiem and Coombe, 1997), FloryHuggins theory (Nakhli et al., 2011), scaling models (Kord and Ayatollahi, 2012), regular solution theory (Akbarzadeh et al., 2005; Alboudwarej et al., 2003), or Equation of State (EOS) based models (Arya et al., 2015; Gonzalez et al., 2005; Gonzalez et al., 2008; Li and Firoozabadi, 2010).

The precipitated asphaltene particles need to be transported from the fluid bulk to the wall surface for deposition to occur. Generally, within a thin fluid layer adjacent to the wall, molecular diffusion dominates particle transport (Mirzayi et al., 2013). Outside this layer, particle transport relies on convection, diffusion, thermophoresis etc. Escobedo and Mansoori (2010) considered only the effects of eddy diffusion and inertia for particle transport. Darabi et al. (2014) proposed three transport mechanisms: Brownian diffusion, inertia and impaction respectively for small $(<1 \mu \mathrm{m})$, medium and large particles. Shirdel et al. (2012) employed the models of Friedlander and Johnstone (1957), Beal (1970), Escobedo and Mansoori (1995), and Cleaver and Yates (1975) for particle transport in oil flow with asphaltene deposition. In addition to these four models, the models of Lin et al. (1953) and El-Shobokshy and Ismail (1980) were also validated by Paes et al. (2015). Both Shirdel et al. (2012) and Paes et al. (2015) recommended the use of Beal model (Beal, 1970) for asphaltene particle transport.

Modeling of asphaltene deposition describes the attaching process of precipitated asphaltene particles. Jamialahmadi et al. (2009) developed a mechanistic model for deposition considering oil velocity, precipitated asphaltene concentration, and bulk and surface temperature. Escobedo and Mansoori (2010) proposed an analytical model to determine heavy-organic particle deposition for fully-developed turbulent flows. Mirzayi et al. (2013) analyzed the gravity, shear-induced, thermophoretic, drag and buoyancy forces on asphaltene particles to determine deposition velocity. Haghshenasfard and Hooman (2015) modeled asphaltene deposition as a thermal cracking kinetic phenomenon with surface chemical reaction. Their results were validated against the experimental data of Jamialahmadi et al. (2009). In a most recent work, Kor and Kharrat (2016a) treated deposition rate as a product of the total transport coefficient, sticking probability, and particle concentration gradient between the bulk and surface. 
For prediction of asphaltene deposition in wellbores/pipelines, the abovementioned models for precipitation, particle transport and deposition need to be combined and fully-coupled to a flow model. Ramirez-Jaramillo et al. (2006) developed a multiphase multicomponent hydrodynamic model for asphaltene deposition in production pipelines. The model consists of a thermodynamic module for asphaltene precipitation using SAFT-VR EOS (Statistical Associating Fluid Theory for Potentials of Variable Range) and a transport module for particle transport and deposition using semi-empirical multiphase flow correlations.

Soulgani et al. (2009) employed a thermodynamic asphaltene precipitation model for predicting the precipitated asphaltene particle concentration, a hydrodynamic well model based on the correlation of Beggs and Brill (1973) for modeling flow, and a fitted correlation for modeling asphaltene deposition. Eskin et al. (2011) assumed that only particles smaller than a critical size can deposit in pipelines. Their model consists of a particle size distribution module (for transient particle size distribution) and a particle transport module (for calculating particle mass fluxes driven by Brownian, turbulence and turbophoresis). The mass of asphaltene deposit is determined from the total particle mass flux and the shear removal of deposit which is accounted for via an experimental correlation.

Vargas et al. (2010) proposed a numerical model with asphaltene precipitation, aggregation, particle transport and deposition considered simultaneously. Asphaltene precipitation rate is assumed proportional to the difference between the actual dissolved asphaltene concentration and the equilibrium asphaltene concentration. The equilibrium concentration is determined by a thermodynamic module using PC-SAFT EOS (Perturbed-Chain Statistical Association Fluid Theory). Particle transport is assumed driven by combined advection-diffusion. Asphaltene aggregation and deposition are treated as pseudo-first order reactions. Kurup et al. (2011) reduced this model to one-dimension and replaced the original diffusion term by an axial dispersion term to account for turbulent effect. Furthermore, Kurup et al. (2012) proposed a protocol to apply the model for oil field scenarios.

In a recent article, Kor and Kharrat (2016b) developed a model to predict asphaltene deposit profile in a wellbore during natural production. This model includes hydrodynamic modeling of multiphase flow, radial heat transfer, thermodynamic modeling of asphaltene precipitation, and asphaltene deposition.

In these above studies, the assumption that the formed deposit layer is thin enough and has no effect on the velocity and pressure fields is frequently made in the light of the modeling complexity of a moving boundary. The effect of the finite deposit layer thickness has not been considered in these studies. In fact, as the deposit layer evolves over time, the flow fields are altered, which in turn affects the temperature and pressure conditions and eventually the precipitation and deposition processes. Besides, according to available field data, the measured deposit layers block substantial flow area of wellbores, e.g. 44\% in Hassi Messaoud field (Haskett and Tartera, 1965), 60\% in South Kuwait's Marrat field (Kabir et al., 2001), and 55\% in West Kuwait's Marrat field (Alkafeef et al., 2003). Evidently, asphaltene deposit layer is usually not thin and therefore should be taken into account in the modeling procedure. The present work is undertaken in this direction by developing a numerical model for asphaltene deposition in wellbores/pipelines with the effect of evolving deposit layer accounted for in a coupled manner to the flow and the deposition process itself.

The remainder of this article is divided into six sections. A short problem description together with the modeling framework is presented in Section 2. Section 3 details the mathematical formulation of the two modules in the proposed model: a Transport Module and a Thermodynamic Module. In Section 4, the method to integrate these two modules is discussed. After the Thermodynamic 
Module is verified and validated in Section 5, the integrated model is applied to investigate oil field asphaltene deposition problem in Section 6. Finally, a brief conclusion is also given.

\section{Problem Description}

At reservoirs, all asphaltenes are miscible in oil as dissolved asphaltenes due to the favorable highpressure high-temperature condition. Dissolved asphaltenes are predominant asphaltene nanoaggregates (with a particle size of 2 to $3 \mathrm{~nm}$ ) and their clusters (generally consisting of 6 to 8 nanoaggregates) (Indo et al., 2009; Mullins, 2010). While as oil flows up (see the schematic in Fig. 1), both $p$ and $T$ drop continuously decreasing the stability of asphaltene in oil. Upon the asphaltene precipitation onset condition, these asphaltene nano-aggregates and clusters can agglomerate to form intermediate particles referred to as precipitated asphaltene particles of a size typically $350 \mathrm{~nm}$ (Vargas et al., 2014). The precipitated asphaltene particles can stick together to constitute larger aggregated asphaltene particles with a particle size $>1 \mu \mathrm{m}$ (Vargas et al., 2014). Because of drag, aggregated asphaltene particles are mostly carried by flow downstream and do not deposit. However, whilst carried downstream by flow, precipitated asphaltene particles which are smaller can simultaneously diffuse radially to the near-wall region. After reaching the wall or the deposit front, some of these particles will attach to it and become deposits. As more particles deposit, the asphaltene deposit layer grows gradually and the crude oil volume fraction ( $\alpha$, defined in eq. 1 ) decreases. From the definition of $\alpha$, deposit layer thickness $(\delta$ ) can be calculated easily using eq. (2).

$$
\begin{aligned}
& \alpha=\frac{V_{f}}{V_{C V}}=\frac{r^{2}}{R^{2}} \\
& \delta=(1-\sqrt{\alpha}) R
\end{aligned}
$$

where $V_{f}$ is the volume of the effective flow passage, $V_{C V}$ is the volume of the control volume (CV), $r$ is the radius of the effective flow passage, and $R$ is the original radius of the wellbore/pipeline.
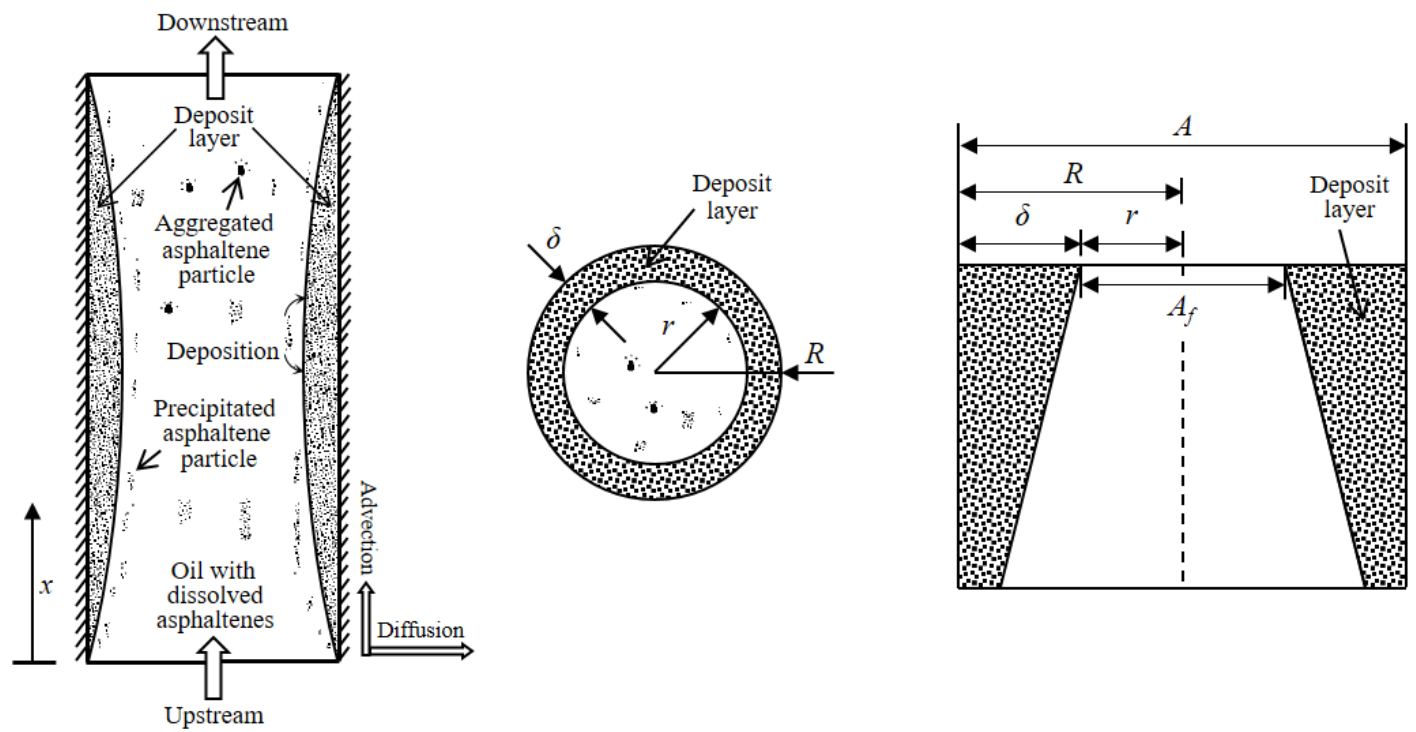

(a) wellbore/pipeline

(b) cross-sectional view

(c) control volume (CV)

Fig. 1. Schematic of oil transport in a circular wellbore/pipeline.

According to the aforementioned problem description, four components should be included in a complete asphaltene deposition model to give accurate predictions of all the physics involved: (1) Asphaltene Precipitation to quantify the amount of precipitated asphaltene particles formed in each $\mathrm{CV}$ at the given $p$ and $T$ condition, (2) Fluid Transport to solve for $u$ and $p$ fields along the wellbore/pipeline, (3) Particle Transport to predict the distributions of dissolved, precipitated and aggregated asphaltenes, and (4) Asphaltene Deposition to model the attachment of precipitated asphaltene particles onto the deposit front. In general, these four components are strongly coupled 
to each other. From a model implementation perspective, these four components can be assembled into a Thermodynamic Module and a Transport Module, as illustrated in Fig. 2.

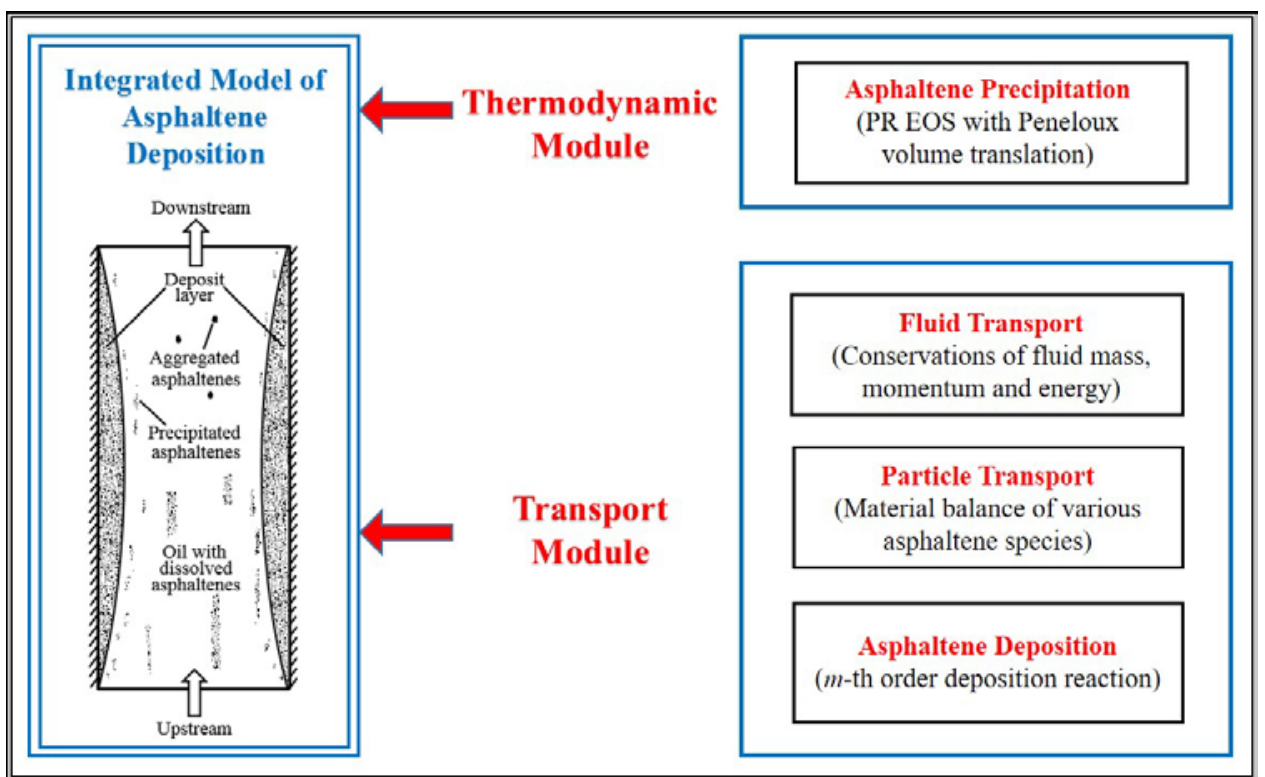

Fig. 2. Modeling framework of the proposed asphaltene deposition model.

\section{Mathematical Formulation}

\subsection{Assumptions}

In the present study, the following assumptions are made:

(1) Single-phase flow.

(2) Oil density $\left(\rho_{o i l}\right)$ and viscosity $\left(\mu_{o i l}\right)$ depend only on $p$ and $T$.

(3) Only precipitated asphaltene particles can deposit.

(4) The deposit layer is rigid solid like without shear removal.

(5) Constant deposit density $\left(\rho_{\text {dep }}\right)$.

\subsection{Transport Module}

The Transport Module aims at modeling Fluid Transport, Particle Transport and Asphaltene Deposition on the basis of a unidirectional one-dimensional one-way approach developed for large length-to-diameter scenarios. The main features, derivation, discretization and solution procedure of this module have been discussed in our other article (Guan et al., 2018). In this section, only its mathematical formulation is presented.

\subsubsection{Fluid Transport}

Fluid Transport is governed by the conservations of fluid mass, momentum and energy as

$$
\frac{\partial}{\partial t}(\rho \alpha)+\frac{\partial}{\partial x}(\rho \alpha u)=-\alpha \dot{R}_{d e p}
$$

where $t$ is the time, $x$ is the axial coordinate, $\rho$ is the crude oil density, $u$ is the average axial velocity, $\dot{R}_{d e p}$ is the asphaltene deposition rate, $p$ is the average pressure at a cross-section, $f_{w}$ is the volumetric frictional force, $c_{p}$ is the specific heat, $T$ is the temperature, and $\dot{R}_{T}$ is the volumetric energy sources/sinks. 
The total viscous force acting on the fluid in a CV is

$$
\int_{C V} f_{w} d V=\tau(2 \pi r d x)
$$

where $\tau$ is the local shear stress given by

$$
\tau=\frac{1}{2} f \rho u^{2}
$$

For a surface with a roughness of $\varepsilon$, the local Fanning friction factor $f$ is determine from (Colebrook et al., 1939; Moody, 1944)

$$
f= \begin{cases}16 / \operatorname{Re} & , \text { if } \operatorname{Re}<4000 \\ \frac{1}{\sqrt{f}}=-4.0 \log _{10}\left(\frac{\varepsilon / D}{3.7}+\frac{1.256}{\operatorname{Re} \sqrt{f}}\right) & \text {,if } 4000 \leq \operatorname{Re}<10^{8}\end{cases}
$$

where $D=2 R$ is the wellbore/pipeline diameter, and the Reynolds number Re is defined as

$$
\operatorname{Re}=\frac{\rho u(2 r)}{\mu}
$$

where $\mu$ is crude oil viscosity.

\subsubsection{Particle Transport}

Particle Transport is governed by the material balance of dissolved asphaltene and precipitated asphaltene particles as

$$
\begin{gathered}
\frac{\partial}{\partial t}\left(\alpha C_{d i s}\right)+\frac{\partial}{\partial x}\left(\alpha u C_{d i s}\right)=-\alpha \dot{R}_{p r e} \\
\frac{\partial}{\partial t}\left(\alpha C_{p r e}\right)+\frac{\partial}{\partial x}\left(\alpha u C_{p r e}\right)=\alpha\left(\dot{R}_{\text {pre }}-\dot{R}_{\text {dep }}-\dot{R}_{\text {agg }}\right)
\end{gathered}
$$

where $C_{d i s}$ is the dissolved asphaltene concentration, $\dot{R}_{\text {pre }}$ is the asphaltene precipitation rate, $C_{\text {pre }}$ is the precipitated asphaltene concentration, and $\dot{R}_{a g g}$ is the asphaltene aggregation rate.

\subsubsection{Asphaltene Deposition}

The deposition rate of precipitated asphaltene particles is modeled by an $m$-th order kinetic reaction approach as

$$
\dot{R}_{\text {dep }}=k_{\text {dep }} C_{\text {pre }}^{m_{\text {dep }}}
$$

where $k_{\text {dep }}$ is the deposition rate constant, and $m_{\text {dep }}$ is the order of deposition reaction. Similarly, the aggregation rate of precipitated asphaltene particles is modeled as

$$
\dot{R}_{\text {agg }}=k_{\text {agg }} C_{\text {pre }}^{m_{\text {agg }}}
$$

with $k_{a g g}$ and $m_{\text {agg }}$ denoting respectively the aggregation rate constant and the order of aggregation reaction. For simplicity, only first order deposition and aggregation reactions are considered in this article, i.e. $m_{\text {dep }}=m_{\text {agg }}=1$. If desired, higher order expressions can be employed.

\subsubsection{Crude Oil Volume Fraction}

The rate of change of deposit in a CV is

$$
\frac{d}{d t} \int_{C V} \rho_{\text {dep }}(1-\alpha) d V=\int_{C V} \dot{R}_{d e p} d V
$$

where $\rho_{\text {dep }}$ is the density of asphaltene deposits. For constant $\rho_{\text {dep }}$,

$$
\frac{d \alpha}{d t}=-\frac{\dot{R}_{d e p}}{\rho_{d e p}}
$$




\subsection{Thermodynamic Module}

The Thermodynamic Module is dedicated to model Asphaltene Precipitation and to predict the crude oil density and viscosity over a range of $p$ and $T$ conditions.

\subsubsection{Asphaltene Precipitation}

Taking both asphaltene precipitation and re-dissolution into account, asphaltene precipitation rate $\dot{R}_{\text {pre }}$ is modeled by (Vargas et al., 2010)

$$
\dot{R}_{p r e}= \begin{cases}k_{p r e}\left(C_{d i s}-C_{e q}\right) & \text {,if } C_{d i s} \geq C_{e q} \\ -k_{d i s} C_{p r e} & \text {,if } C_{d i s}<C_{e q}\end{cases}
$$

where $k_{\text {pre }}$ and $k_{\text {dis }}$ are respectively the precipitation and re-dissolution rate constants, and $C_{e q}$ is the equilibrium asphaltene concentration at a specific $p$ and $T$ condition. Physically, $C_{e q}$ represents the maximum amount of dissolved asphaltene that can be present in a unit volume of crude oil. When the actual dissolved asphaltene concentration $\left(C_{d i s}\right)$ in oil is higher than $C_{e q}$, asphaltene precipitation occurs. On the contrary, when $C_{\text {dis }}$ falls below $C_{e q}$, some of the precipitated asphaltene particles can re-dissolve into the oil.

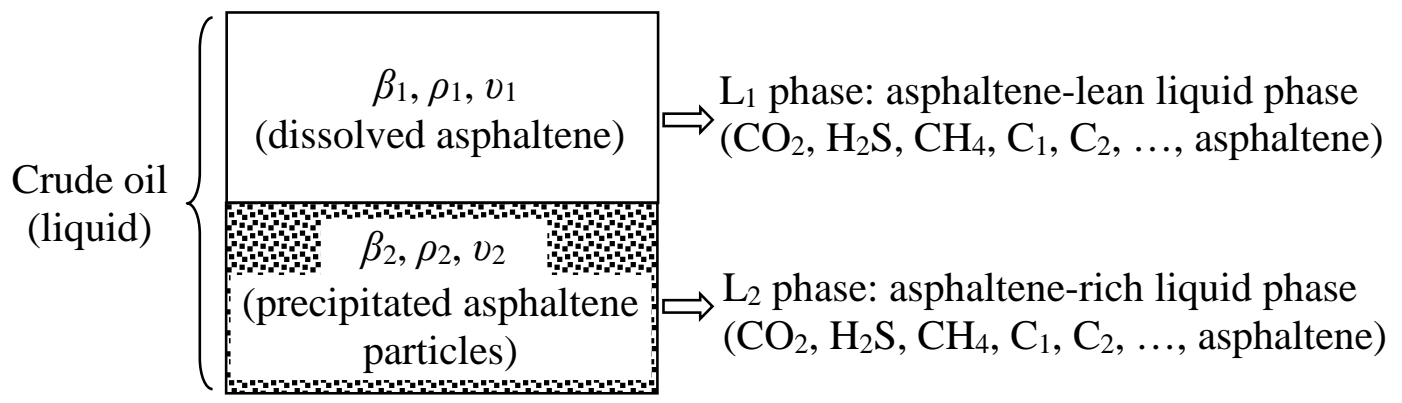

Fig. 3. Schematic of the two liquid phases assumed in crude oil.

As depicted in Fig. 3, two liquid phases are assumed to coexist in the liquid-state crude oil of interest: an asphaltene-lean liquid phase $\left(\mathrm{L}_{1}\right)$ and an asphaltene-rich liquid phase $\left(\mathrm{L}_{2}\right)$. Besides, precipitated asphaltene particles are assumed to exist only in the $\mathrm{L}_{2}$ phase. Under these assumptions, $C_{e q}$ in a unit of $\mathrm{kg} / \mathrm{m}^{3}$ is evaluated by

$$
C_{e q}=\frac{\beta_{1} x_{a s p h} M W_{a s p h}}{\beta_{1} v_{1}+\beta_{2} v_{2}}
$$

where $x_{a s p h}$ is the mole fraction of the asphaltene pseudo-component in $\mathrm{L}_{1}$ phase, $M W_{a s p h}$ is the molar weight of the asphaltene pseudo-component, and $\beta$ and $v$ denote respectively the mole fraction and molar volume of a liquid phase. The subscripts "1" and "2" denote the properties corresponding to $\mathrm{L}_{1}$ and $\mathrm{L}_{2}$ phases respectively. It should be stressed here that the concept of multiple phases takes effect only within the Thermodynamic Module. In fact, $\mathrm{L}_{1}$ and $\mathrm{L}_{2}$ phases are miscible with each other. In other words, there is only one liquid fluid for the crude oil flow, and thus in the Transport Module.

\subsubsection{Crude Oil Density and Viscosity}

The crude oil density at specific $p$ and $T$ is calculated by

$$
\rho_{\text {oil }}=\frac{\beta_{1} \sum_{i=1}^{N_{c}} x_{i} M W_{i}+\beta_{2} \sum_{i=1}^{N_{c}} y_{i} M W_{i}}{\beta_{1} v_{1}+\beta_{2} v_{2}}
$$

where $x_{i}$ and $y_{i}$ represent respectively the mole fractions of the $i$-th component in $\mathrm{L}_{1}$ and $\mathrm{L}_{2}$ phases, and $N_{c}$ is the total number of components in crude oil.

To calculate $\mu_{\text {oil }}$, the corresponding states viscosity model (Lindeloff et al., 2004; Pedersen and Fredenslund, 1987; Pedersen et al., 1984) is employed as described in APPENDIX A. Note that this 
model is the default principle for viscosity calculations in the commercial software PVTSim V20.0. Its validity and versatility have been demonstrated in a number of engineering practices.

\subsubsection{Multicomponent Multiphase Flash Calculation}

In the calculation of $C_{e q}, \rho_{\text {oil }}$ and $\mu_{\text {oil }}$, the mole fraction of all components (i.e. $x_{i}$ and $y_{i}$ for $i=1$ to $N_{c}$ ) and the molar properties of $\mathrm{L}_{1}$ and $\mathrm{L}_{2}$ phases $\left(\beta_{i}\right.$ and $v_{i}$ for $i=1$ to 2 ) at specific $p$ and $T$ should be determined first. To achieve this, an in-house multicomponent multiphase flash calculation program is developed by embedding the Peng-Robinson EOS (Peng and Robinson, 1976; Robinson and Peng, 1978) and the Peneloux volume translation technique (Péneloux et al., 1982) in an isothermal flash calculation algorithm proposed by Michelsen (Michelsen, 1982a; Michelsen, 1982b). This flash calculation program was coded in the platform of Intel Visual Fortran 2012 in Guan (2016). A brief description and flowcharts of this program are given in APPENDIX B.

\section{The Integrated Model}

\subsection{Integration of Two Modules}

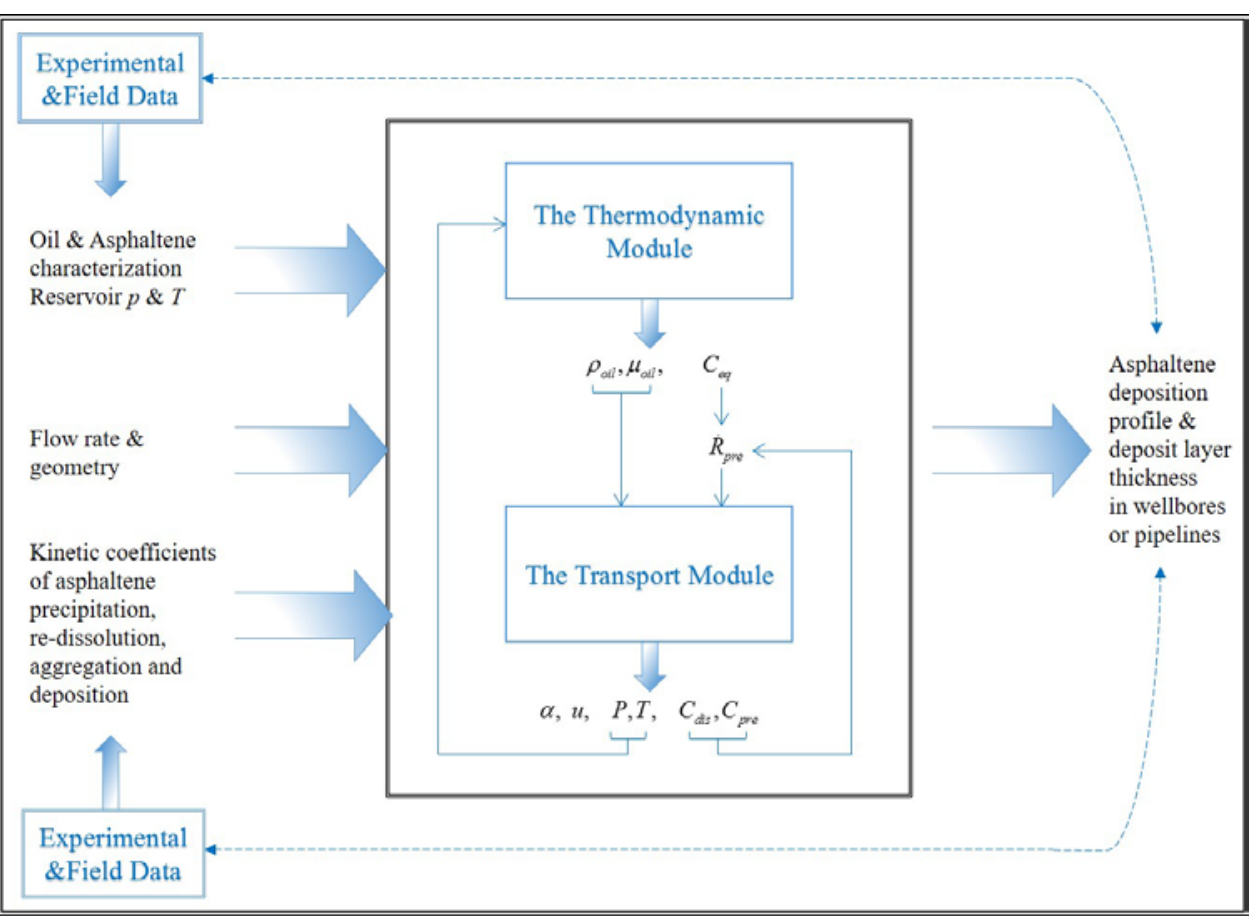

Fig. 4. The structure of the proposed asphaltene deposition model.

Fig. 4 is the schematic representation of the proposed asphaltene deposition model which consists of a Thermodynamic Module and a Transport Module. From the Thermodynamic Module, $\rho_{\text {oil }}, \mu_{\text {oil }}$, and $C_{e q}$ are predicted followed by the calculation of $\dot{R}_{\text {pre }}$ at the given $p$ and $T$. Then, the three parameters $\rho_{\text {oil }}, \mu_{\text {oil }}$, and $\dot{R}_{\text {pre }}$ are exported to the Transport Module for determining the distributions of $\alpha, u, p, T, C_{d i s}$ and $C_{p r e}$ in the wellbore/pipeline. In turn, the predicted $p, T, C_{d i s}$ and $C_{p r e}$ are exported to the Thermodynamic Module for the next iteration of $\rho_{\text {oil }}, \mu_{\text {oil }}$, and $\dot{R}_{\text {pre. }}$ As such, the Thermodynamic Module and the Transport Module are strongly coupled.

The look-up table approach suggested by Vargas et al. (2010) is adopted for integrating these two modules. In this approach, prior to each simulation, the Thermodynamic Module is first employed to generate three tables for $\rho_{o i l}, \mu_{o i l}$, and $C_{e q}$ at various $p$ and $T$ conditions. During simulation, the Transport Module will continually look up these tables to determine the thermodynamic properties at the known $p$ and $T$. In this manner, there is no need to solve the Thermodynamic Module in tandem with the Transport Module during each iteration. In general, 5 to 15 iterations are needed 
for the variables of interest in an elemental CV to reach converged solutions. On the other hand, the multicomponent multiphase flash calculation in the Thermodynamic Module is also an iterative process that consumes substantial computational efforts. Therefore, the look-up table approach is largely beneficial in reducing computational time.

A typical look-up table with a pressure range of $\left[p_{1}, p_{m}\right]$ and a temperature range of $\left[T_{1}, T_{n}\right]$ is exemplified in Table 1 , where $p_{1}, p_{m}, T_{1}$, and $T_{n}$ (i.e. the pressures and temperatures at reservoir and wellhead) are usually provided in oil field data. The increments between two consecutive pressures and temperatures are set as 0.5 bar and $0.5 \mathrm{~K}$ respectively. Altogether, $m \times n$ calculations should be performed using the Thermodynamic Module to establish the required table. During simulation, a bisection method is first employed by the Transport Module to search for the smallest intervals [ $p_{i}$, $\left.p_{i+1}\right]$ and $\left[T_{j}, T_{j+1}\right]$ that encompass the specific $p$ and $T$. Then, the desired output $\left.\phi\right|_{p, T}$ is determined through a linear interpolation as

$$
\left.\phi\right|_{p, T}=\left.\phi\right|_{p, T_{j}}+\frac{\left.\phi\right|_{p, T_{j+1}}-\left.\phi\right|_{p, T_{j}}}{T_{j+1}-T_{j}}\left(T-T_{j}\right)
$$

where $\left.\phi\right|_{p, T_{j}}$ and $\left.\phi\right|_{p, T_{j+1}}$ are computed from

$$
\begin{gathered}
\left.\phi\right|_{p, T_{j}}=\phi(i, j)+\frac{\phi(i+1, j)-\phi(i, j)}{p_{i+1}-p_{i}}\left(p-p_{i}\right) \\
\left.\phi\right|_{p, T_{j+1}}=\phi(i, j+1)+\frac{\phi(i+1, j+1)-\phi(i, j+1)}{p_{i+1}-p_{i}}\left(p-p_{i}\right)
\end{gathered}
$$

Table 1. The format of the look-up table generated by the Thermodynamic Module

\subsection{Solution Method}

The governing equations in the Transport Module (eqs. 3-5, 7-8) can be reformulated generally as

$$
\frac{\partial}{\partial t}(\tilde{\rho} \tilde{\phi})+\frac{\partial}{\partial x}(\tilde{\rho} \tilde{\phi} u)=\alpha S_{\tilde{\phi}}
$$

where $\tilde{\phi}$ represents the generic variable of interest, $\tilde{\rho}$ the "density", and $S_{\tilde{\phi}}$ the sources/sinks for the dependent variable per unit total (oil + deposit) volume. Table 2 shows the meanings of these three variables corresponding to different governing equations.

Table 2. Governing equations and meanings of various terms. Equation

$\begin{array}{llll}\tilde{\phi} & \tilde{\rho} & S_{\tilde{\phi}} & \text { eq. }\end{array}$




\begin{tabular}{ccccc}
\hline Continuity & 1 & $\rho$ & $-\dot{R}_{\text {dep }}$ & (3) \\
Momentum & $u$ & $\rho$ & $-\frac{\partial p}{\partial x}+\rho g-\frac{f_{w}}{\alpha}$ & (4) \\
Dissolved Asphaltene & $C_{d i s}$ & 1 & $-\dot{R}_{p r e}$ & (5) \\
Precipitated Asphaltene & $C_{p r e}$ & 1 & $\dot{R}_{\text {pre }}-\dot{R}_{\text {dep }}-\dot{R}_{\text {agg }}$ & (7) \\
Energy & $T$ & $\rho c_{p}$ & $\dot{R}_{T}$ & $(8)$ \\
\hline
\end{tabular}

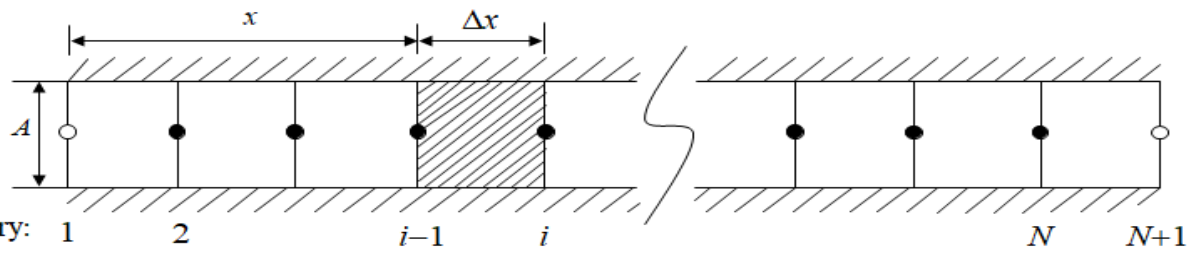

Fig. 5. Schematic of the discretized computational domain.

The general transient convection equation is solved using the finite volume method (Patankar, 1980; Versteeg and Malalasekera, 2007) on a regular mesh arrangement shown in Fig. 5. The computational domain is divided into $N$ non-overlapping CVs. All variables are stored at the CV boundaries, labeled with either filled or open circles. Internal nodes are depicted using filled circles, while boundary grid points are identified using open circles. Note that the sizes of the CVs need not be uniform. A fully-implicit scheme where the value of $\tilde{\phi}$ at time $t+\Delta t$ prevails over the time step $\Delta t$ is used to discretize the time variation. For compactness, we shall use $n-1$ and $n$ to denote time $t$ and $t+\Delta t$ respectively. A "fully-implicit" spatial differencing is also used to discretize the spatial variation between $i-1$ and $i$. Using these two differencing practices, the general governing equation is discretized as

$$
\left[(\tilde{\rho} \tilde{\phi})_{i}^{n}-(\tilde{\rho} \tilde{\phi})_{i}^{n-1}\right] \frac{\Delta V}{\Delta t}+\left[(\tilde{\rho} \tilde{\phi} u)_{i}^{n}-(\tilde{\rho} \tilde{\phi} u)_{i-1}^{n}\right] A=\left(\alpha S_{\tilde{\phi}}\right)_{i}^{n} \Delta V
$$

Finally, the overall solution algorithm is summarized as follows:

(1) Generate the look-up table using the Thermodynamic Module.

(2) Specify the inlet values at $i=1$ and the initial conditions at $t=0$.

(3) Advance the time step from $t$ to $t+\Delta t$.

a. Advance the spatial location from $i$ to $i+1$ and begin an inner iteration loop.

i. Search for the values of $\rho_{\text {oil }}, \mu_{o i l}$ and $C_{e q}$ at the latest $p$ and $T$ from the prepared look-up table using eq. (16).

ii. Calculate $\dot{R}_{\text {dep }}$ (eq. 9), $\dot{R}_{a g g}$ (eq. 10), $\dot{R}_{\text {pre }}$ (eq. 13) and $f_{w}$ (eq. 6).

iii. Solve for the variables of interest in the sequence of $\alpha$ (eq. 12), $u$ (eq. 3), $p$ (eq. 4), $T$ (eq. 5), $C_{\text {dis }}$ (eq. 7) and $C_{\text {pre }}$ (eq. 8).

iv. Repeat i. to iii. until the solutions converge, then exit the inner loop.

b. Calculate $\delta$ using eq. (1).

c. Update the previous time step values with the current time step solutions.

d. Repeat a. to c. until $i=N+1$, then exit the spatial sweep.

(4) Set $i=1$ and repeat (3) until the desired time is attained.

\section{Verification \& Validation of the Thermodynamic Module}

The verification and validation of the Transport Module have been discussed in our other article (Guan et al., 2017). In this section, the Thermodynamic Module is independently verified against the results of PVTSim V20.0 and validated with the experimental data available in literature. 


\subsection{Asphaltene Precipitation Envelope under Pressure Depletion}

Asphaltene precipitation envelope (APE) defines the region in the $p$ - $T$ space where asphaltene precipitation takes place (Akbarzadeh et al., 2007). It describes the phase behaviors of asphaltene in the oil of interest over a range of $p$ and $T$ conditions. An accurate prediction of APE, to some extent, is the primary target in thermodynamic modeling of asphaltene precipitation. For verification and validation's purposes, the Thermodynamic Module presented in this work is applied to predict the APEs of two oils studied originally by Jamaluddin et al. (2000) (referred to as Oil 1 in this article) and Jamaluddin et al. (2002) (Oil 2). The oil compositions in mole percentage (mol\%) are given in Table C. 1 in Appendix C. Table C.2 shows the binary interaction parameters (BIPs) adopted in this study. The available APE data in terms of upper asphaltene onset pressure (UAOP), bubble pressure (BP) and lower asphaltene onset pressure (LAOP) are summarized in Table C.3. The parameters of these two oils after characterization are shown respectively in Table C.4 and Table C.5.

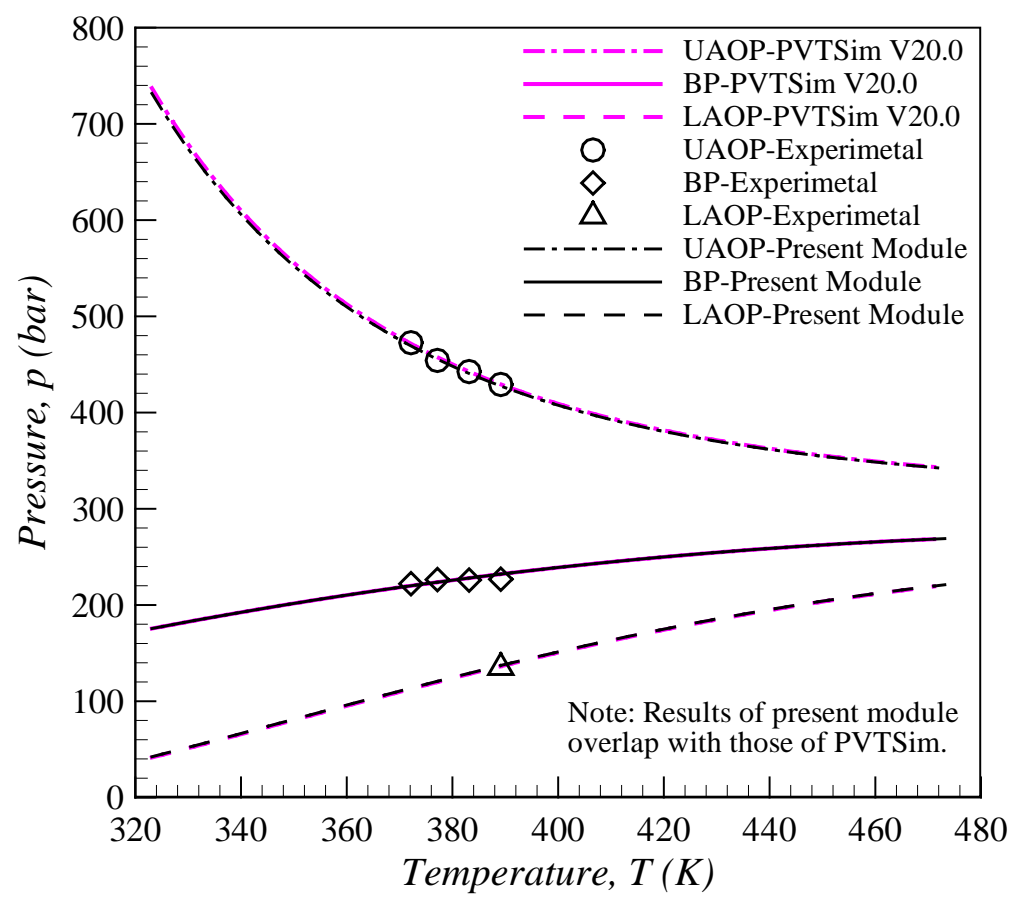

(a) Oil 1 


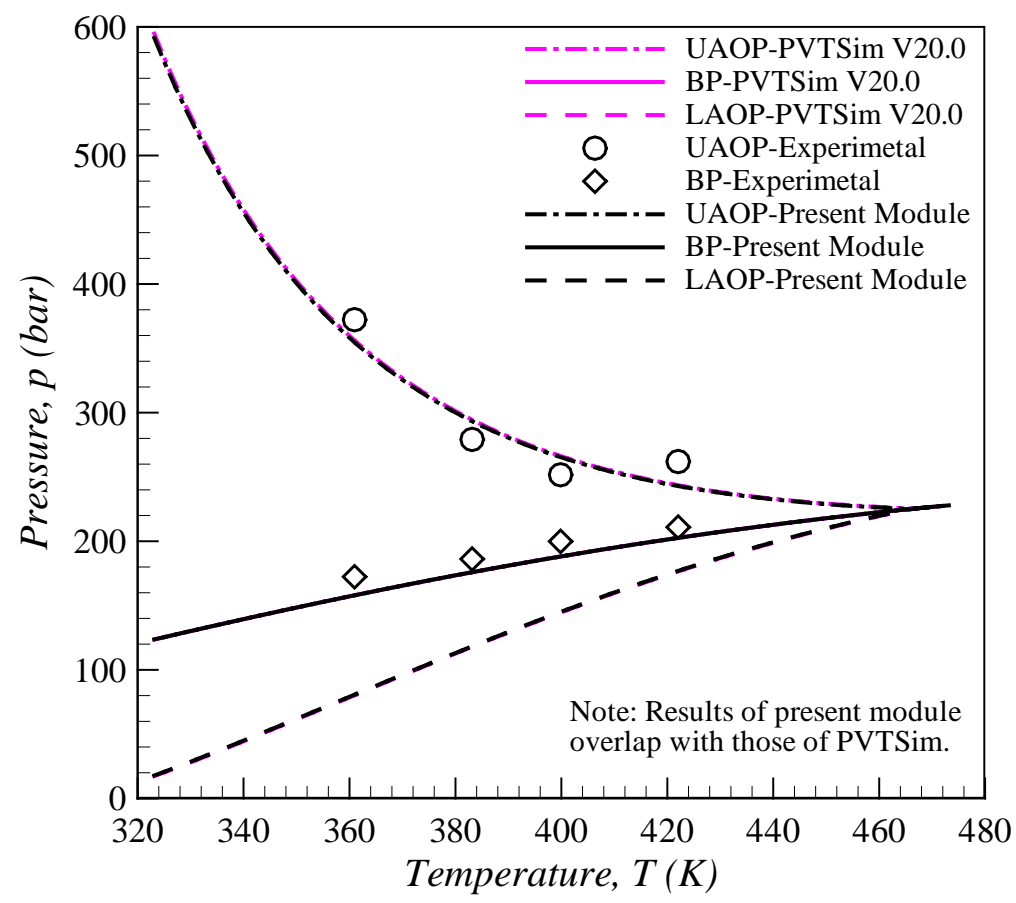

(b) Oil 2

Fig. 6. APE prediction under pressure depletion compared with experimental data of Jamaluddin et al. (2000) (a) and Jamaluddin et al. (2002) (b).

The APE predicted using the Thermodynamic Module is compared with the prediction of PVTSim V20.0 and the experimental data of Jamaluddin et al. (2000) and Jamaluddin et al. (2002) in Fig. 8. For both of these two oils, the Thermodynamic Module gives nearly identical predictions to those of PVTSim V20.0. This effectively verifies the Thermodynamic Module. Besides, for Oil 1 in Fig. 8a, all the predicted UAOP, BP and LAOP curves match very well with the experimental data. As for Oil 2 where no LAOP data is available (Fig. 8b), the predictions of UAOP and BP are in good agreements with the experimental measurements, although the discrepancies between the predicted and the measured BP are slightly larger.

\subsection{Asphaltene Weight Fraction at Varying Pressure but a Fixed Temperature}

In this exercise, the Thermodynamic Module is used to predict asphaltene weight fraction ( $\left.W_{\text {asph }}\right)$ in a crude oil at $T=322 \mathrm{~K}$ but various pressures for validation against the experimental data in (Zhang et al., 2012). The composition of this South Kuwait's Marrat Field oil (Oil 3) in mol\% is given in Table C.1. The asphaltene onset data and bubble points are listed in Table C.6. The employed BIPs are shown in Table C.2, except those between $\mathrm{C}_{1}-\mathrm{C}_{9}$ and the asphaltene pseudo-component are set to 0.065 to match the LAOP measurements. The parameters of Oil 3 after characterization are tabulated in Table C.7. 


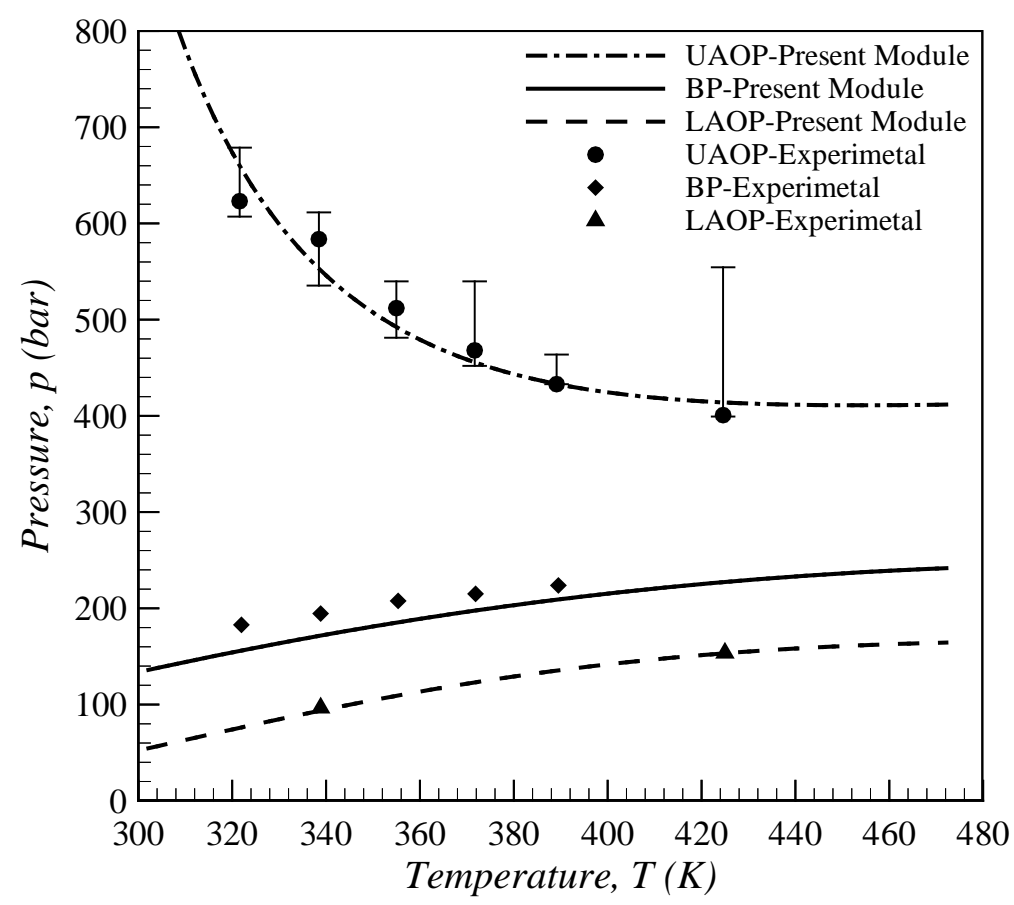

Shown in Fig.7 is the comparisons between the predicted APE and the available experimental asphaltene onset data and bubble points. The Thermodynamic Module predicts UAOP and LAOP accurately. However, BP is slightly underpredicted with an average discrepancy of $10.25 \%$. Besides, the oil density predicted by the developed Thermodynamic Module is $39.83^{\circ} \mathrm{API}$, according with the range of $36^{\circ}-40^{\circ} \mathrm{API}$ reported by Kabir and Jamaluddin (1999). In addition, the asphaltene content in stock tank oil is predicted as $0.545 \mathrm{wt} \%$. This value is in good conformity with the reported data $\left(0.5 \mathrm{wt} \% \mathrm{C}_{7}\right.$-asphaltene), obtained via SARA analysis with n-heptane $\left(\mathrm{C}_{7}\right)$ as solvents (Kabir and Jamaluddin, 1999).

The predicted and measured $w_{a s p h}$ are compared in Fig. 8. It is observed that $w_{a s p h}$ is constant for $p>$ UAOP (about 650 bar). At this condition, only $\mathrm{L}_{1}$ phase exists in oil with all asphaltenes dissolved within it. As $p$ falls below UAOP, asphaltene precipitation occurs leading to a gradual reduction of dissolved asphaltene in the oil. An almost linear decease of wasph is predicted which agrees well with the experimental measurements. After BP, some light components, e.g. $\mathrm{CH}_{4}, \mathrm{C}_{2} \mathrm{H}_{6}$ and $\mathrm{N}_{2}$, begin to liberate from the oil. Since these light components are good asphaltene precipitants, with their gradual liberation, the oil becomes more stable accompanied by the re-dissolution of some precipitated asphaltene particles. Therefore, the predicted wasph increases between BP and LAOP. In this range, the prediction deviates from the experimental data. This may be caused by the underprediction of BP. When $p$ is lower than LAOP, asphaltene precipitation terminates and all precipitated asphaltenes re-dissolve into the oil. Besides, due to the continuous liberation of light components, $w_{a s p h}$ increases as $p$ decreases. All in all, the Thermodynamic Module developed in this work can accurately predict $w_{\text {asph }}$ in accordance with the phase behaviors of Oil 3 at $T=322 \mathrm{~K}$ but $p$ ranging from 800 bar to 20 bar. 


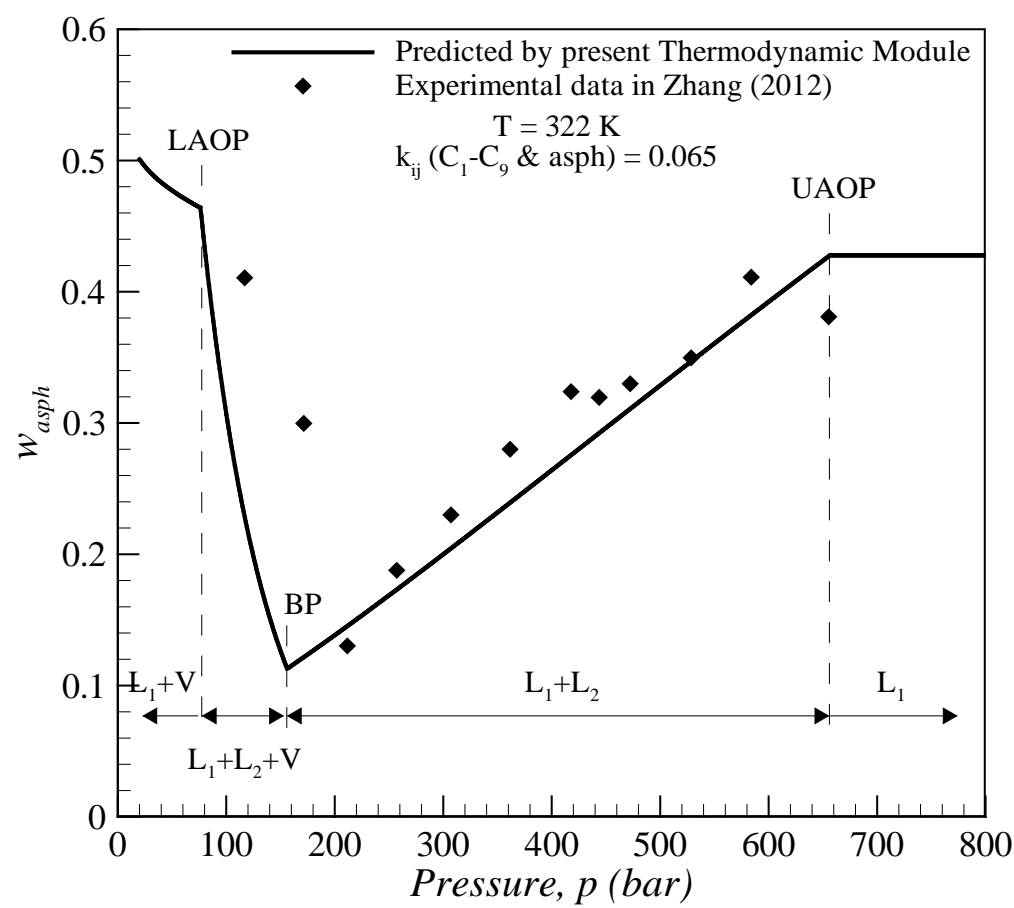

Fig. 8. Prediction of asphaltene wt\% in Oil 3 compared with experiment data in (Zhang et al., 2012).

\section{Case Study: Oil Field Asphaltene Deposition Problems}

After verifying and validating the Transport and Thermodynamic Modules, the integrated model is applied to investigate oil field asphaltene deposition problem in this section. To achieve this, the oil characterization results, APE data (i.e. UAOP, BP, and LAOP) and operating conditions (e.g. $p$ and $T$ at reservoir and wellhead) are required for prediction of asphaltene precipitation (using the Thermodynamic Module). The wellbore/pipeline geometry (i.e. length and diameter), wall surface roughness and oil flow rate are needed for prediction of fluid flow (using the Transport Module). The kinetic coefficients of asphaltene precipitation, re-dissolution, aggregation, and deposition are also necessary to describe these processes. In addition, the asphaltene deposit profile should be available to examine the model's prediction capability. However, to the best knowledge of the authors, there is no oil field asphaltene deposition case in existing literature with a full set of the abovementioned information. Therefore, the asphaltene deposition problem in the oilwell of South Kuwait's Marrat field studied previously by Kurup et al. (2011) is selected in this article with required data extracted from literature and auxiliary assumptions made if needed.

Table 3. Parameters of the South Kuwait’s Marrat oilwell (Kabir et al., 2001)

\begin{tabular}{cccc}
\hline $\begin{array}{c}\text { Wellbore } \\
\text { depth, } L(f t)\end{array}$ & $\begin{array}{c}\text { Wellbore } \\
\text { diameter, } D(\text { in })\end{array}$ & $\begin{array}{c}\text { Oil production } \\
\text { rate, } Q(\mathrm{STB} / \text { day })\end{array}$ & $\begin{array}{c}\text { Surface } \\
\text { roughness, } \varepsilon / D\end{array}$ \\
\hline 15000 & 2.75 & 5000 & 0.000018
\end{tabular}

The parameters of this oilwell are tabulated in Table 3. The kinetic coefficients used in simulation $\left(k_{d i s}=1.8 \times 10^{-3} \mathrm{~s}^{-1}, k_{d i s}=1.7 \times 10^{-2} \mathrm{~s}^{-1}, k_{\text {agg }}=1.8 \times 10^{-3} \mathrm{~s}^{-1}\right.$, and $\left.k_{d e p}=2.1 \times 10^{-4} \mathrm{~s}^{-1}\right)$ are determined by matching the maximum deposit layer thickness in a time duration of two months to 0.55 in (Kabir and Jamaluddin, 1999). 


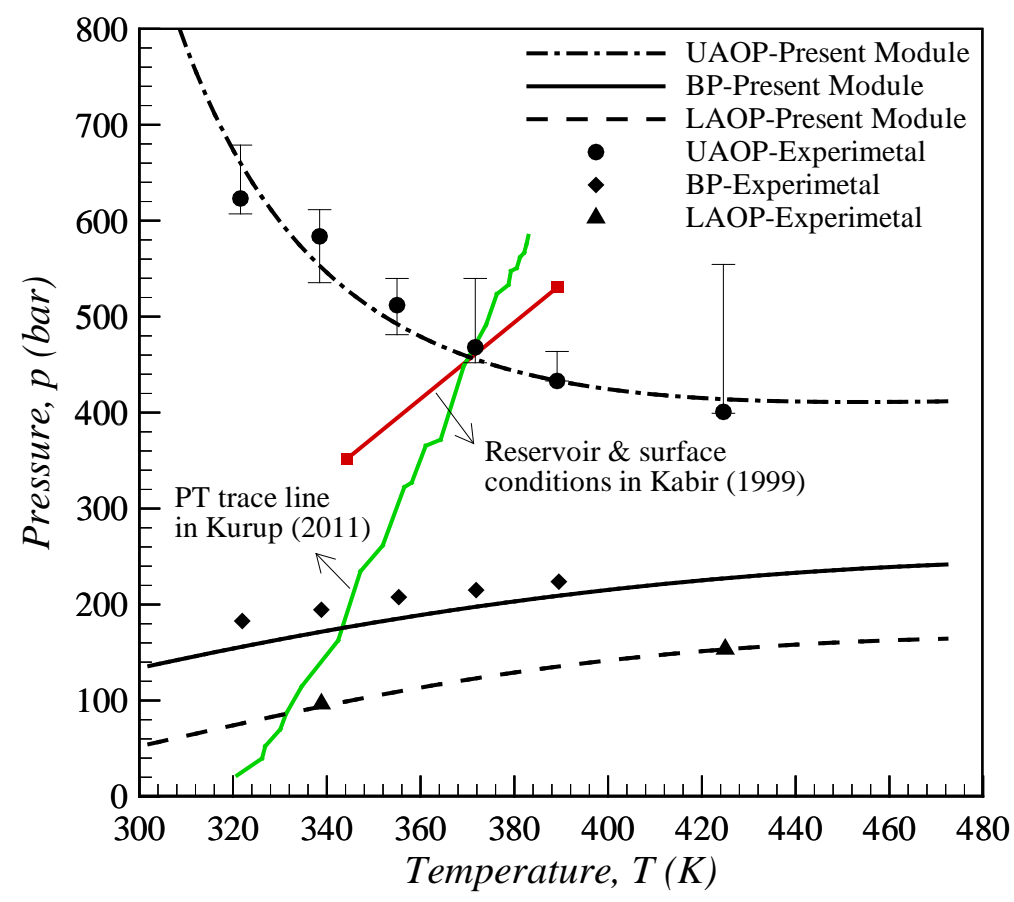

Fig. 9. APE prediction for Oil 3 plotted with two different operating conditions found in (Kabir and Jamaluddin, 1999) and (Kurup et al., 2011).

The crude oil produced from South Kuwait's Marrat field has been studied thermodynamically in Section 5.2. The APE prediction is presented again in Fig. 9 plotted with two different operating conditions found in literature. The $p$ and $T$ at reservoir reported by Kabir and Jamaluddin (1999) are 7700 psia and $241^{\circ} \mathrm{F}\left(530.90\right.$ bar and $389.26 \mathrm{~K}$ ), and those at wellhead are 5100 psia and $160^{\circ} \mathrm{F}$ (351.63 bar and 344.26 K). However, in the work of Kurup et al. (2011), a different operating condition indicated by a $p-T$ trace line was used. This $p-T$ trace line was reported in Chevron's internal database, from which the reservoir condition is determined as 8497 psia and $230^{\circ} \mathrm{F}(585.85$ bar and $383.15 \mathrm{~K}$ ) and the wellhead condition is 321 psia and $118^{\circ} \mathrm{F}$ ( 22.13 bar and $320.93 \mathrm{~K}$ ). Using the present model, study of asphaltene deposition in this oilwell for these two different sets of operating conditions is presented sequentially in the next two subsections.

\subsection{Simulation using the Conditions of Kabir and Jamaluddin (1999)}

Determination of the temperature field from eq. (5) requires the thermal properties of the oil, production string, formation and seawater (offshore). However, not all these information is available. In this case study, a linear temperature distribution is assumed between the surface and reservoir conditions. The velocity at the inlet is calculated as $2.40 \mathrm{~m} / \mathrm{s}$ according to the given oil production rate and wellbore diameter. With these and subjected to the reservoir and wellhead conditions of Kabir and Jamaluddin (1999), the distributions of $\delta, u$ and $p$ in the wellbore are predicted and plotted against well depth in Fig. 10. It can be observed that the spatially and temporally mesh-independent results are achieved by employing $200 \mathrm{CVs}$ with a time step of $8.0 \mathrm{~s}$. Note that the well depth is measured from the surface, i.e. opposite of the oil flow direction.

According to Fig. 10c, $p$ in the wellbore decreases along the streamwise direction and intersects the UAOP curve (pressure when asphaltene precipitation starts) at a well depth of around $9000 \mathrm{ft}$. This explains the occurrence of asphaltene deposition at nearly the same well depth in Fig. 10a. Additionally, $p$ in the wellbore is found to be above BP all time. Theoretically, asphaltene deposition tends to be more severe from UAOP to BP. Thus, the deposit thickness $\delta$ increases continuously as oil flows up over time. This prediction is consistent with the statement reported in Kabir and Jamaluddin (1999) that the asphaltene deposition problem in this oilwell is inevitable when oil production is operated from reservoir state to surface condition. Since $p$ is above BP throughout the wellbore, the flow remains single-phase and pressure drop is dominated by gravity. 
1 The increasingly thicker deposit layer does induce a larger pressure drop as shown in Fig. 10d, but 2 its effect is not significant compared with the overall pressure drop. Nevertheless, the effect of the 3 growing deposit layer on the velocity field in the wellbore is pronounced: $u$ increases along the oil 4 flow direction and over varying from $2.40 \mathrm{~m} / \mathrm{s}$ to at $3.60 \mathrm{~m} / \mathrm{s}$ (Fig. 10b).

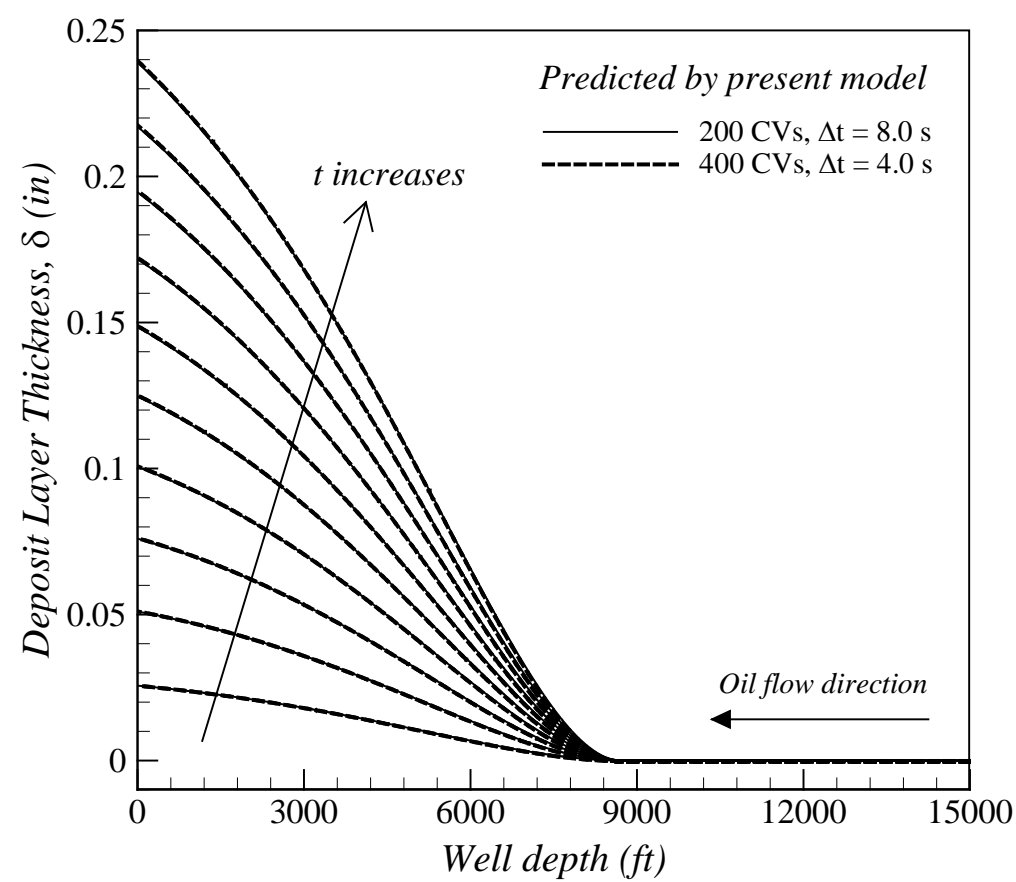

(a) deposit layer thickness

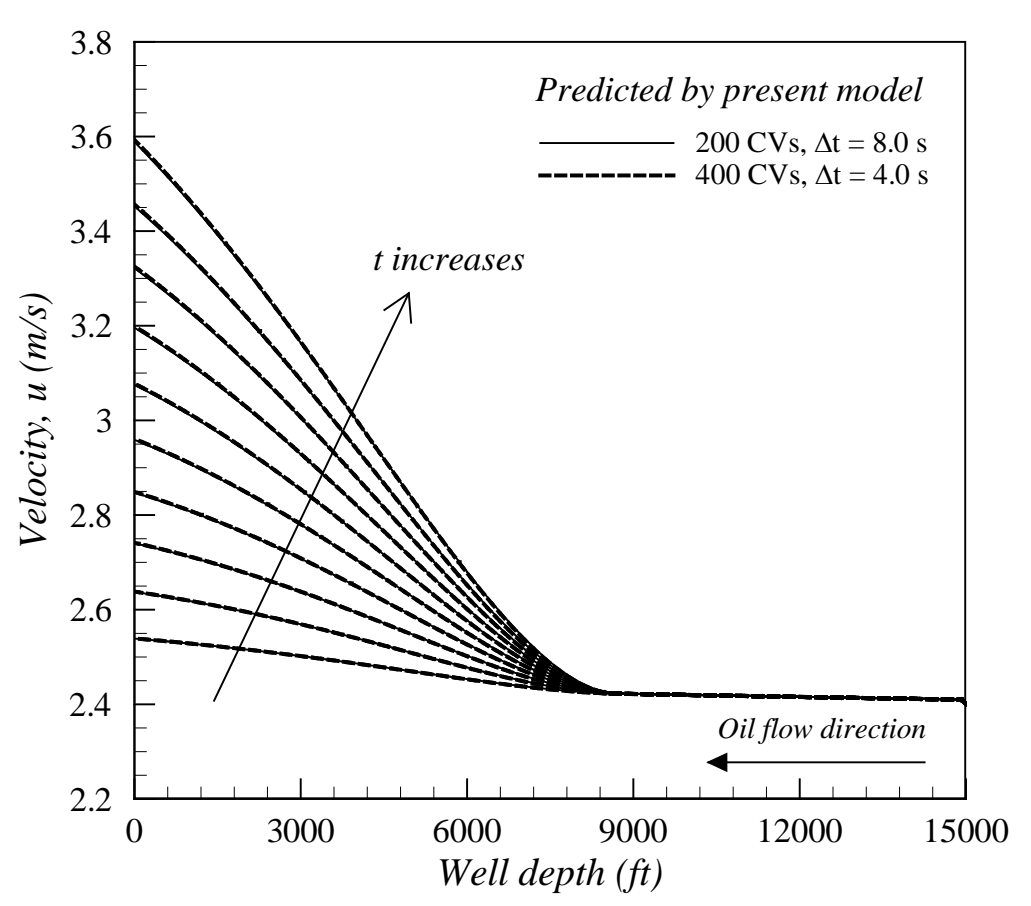

(b) fluid velocity 


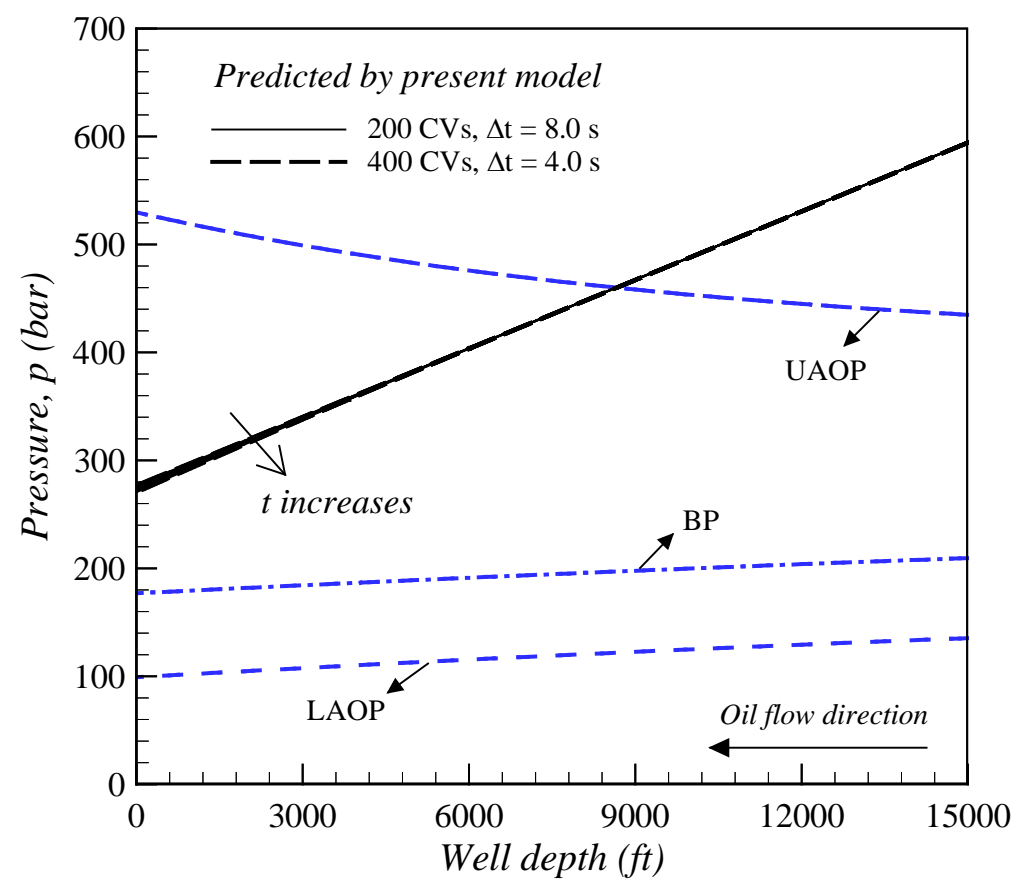

(c) pressure

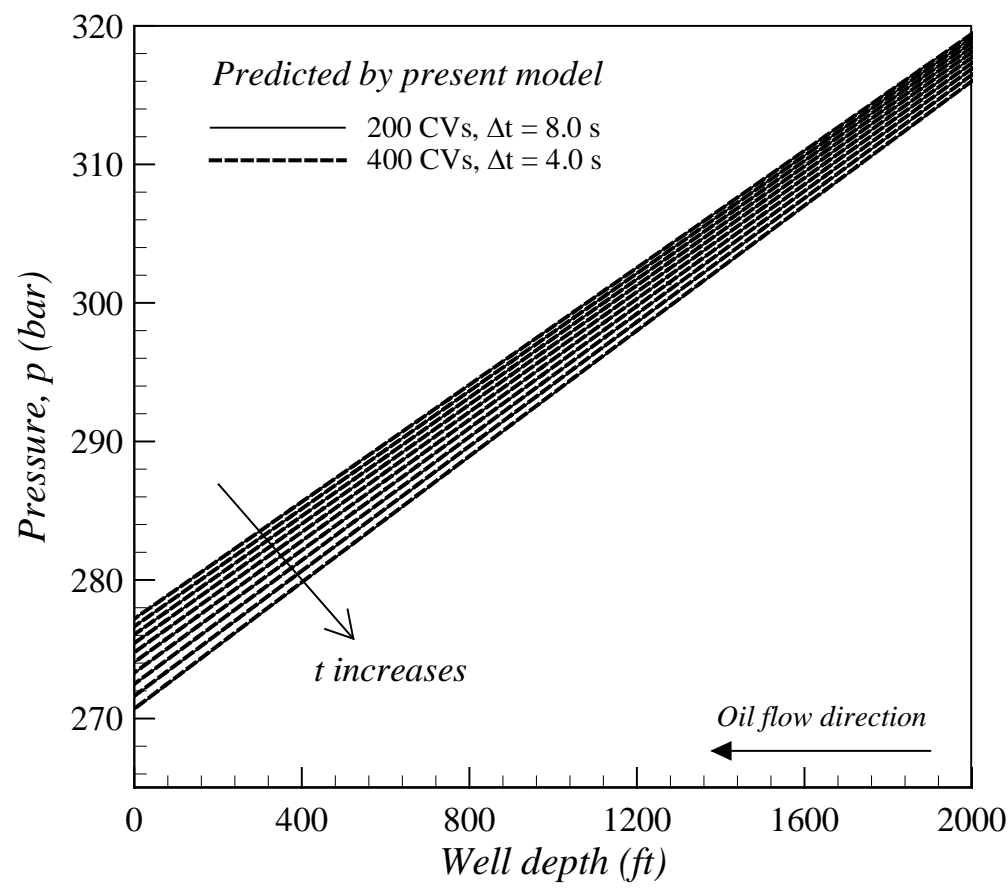

(d) pressure between $0 \sim 2000 \mathrm{ft}$

Fig. 10. Predictions for the South Kuwait's Marrat oilwell using the conditions of Kabir and Jamaluddin (1999) at $t=6,12,18,24,30,36,42,48,54$ and 60 days.

\subsection{Simulation using the Conditions of Kurup et al. (2011)}

The $p-T$ trace line shown in Fig. 9 spans across all those regions divided by the predicted APE. It should be noted that for the regions below BP, another vapor phase is formed coexisting with the $\mathrm{L}_{1}$ and $\mathrm{L}_{2}$ phases in the oil. However, the Fluid Transport component in the developed Transport Module is targeted at single-phase flow only; it is not applicable for two-phase flow and therefore is switched off. Instead, a velocity of $2.40 \mathrm{~m} / \mathrm{s}$ is prescribed throughout the entire wellbore following the approach adopted by Kurup et al. (2011). In addition, linear assumption of $p$ and $T$ variation is made. Based on all the above assumptions, the predicted spatially and temporally mesh-independent $\delta$, $C_{d i s}, C_{e q}$ and $C_{p r e}$ are plotted in Fig. 11. 


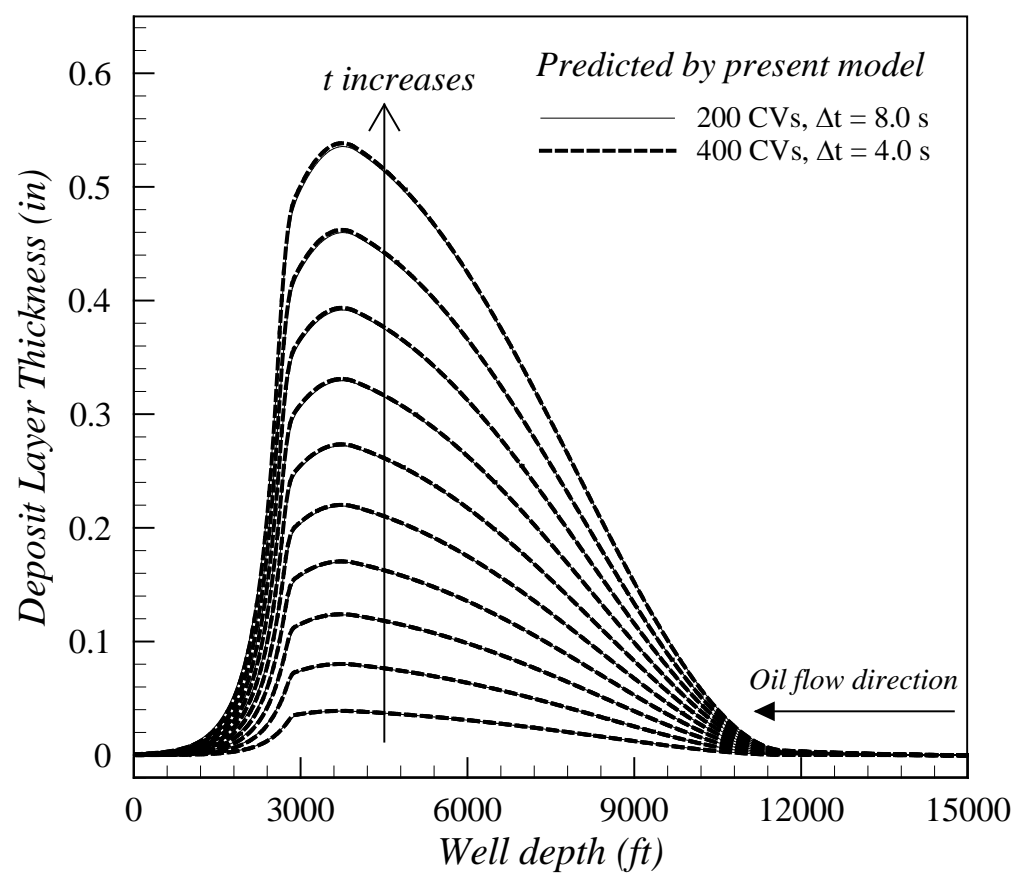

(a) deposit layer thickness $\delta$

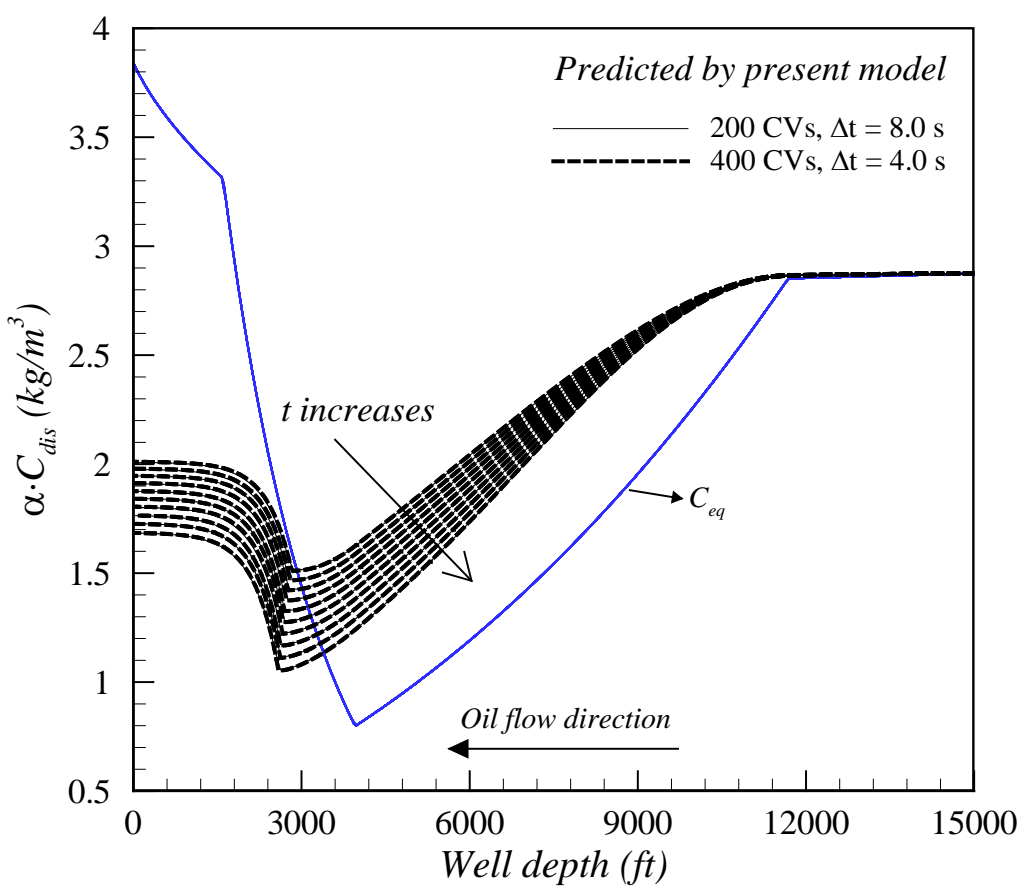

(b) $\alpha C_{\text {dis }}$ 

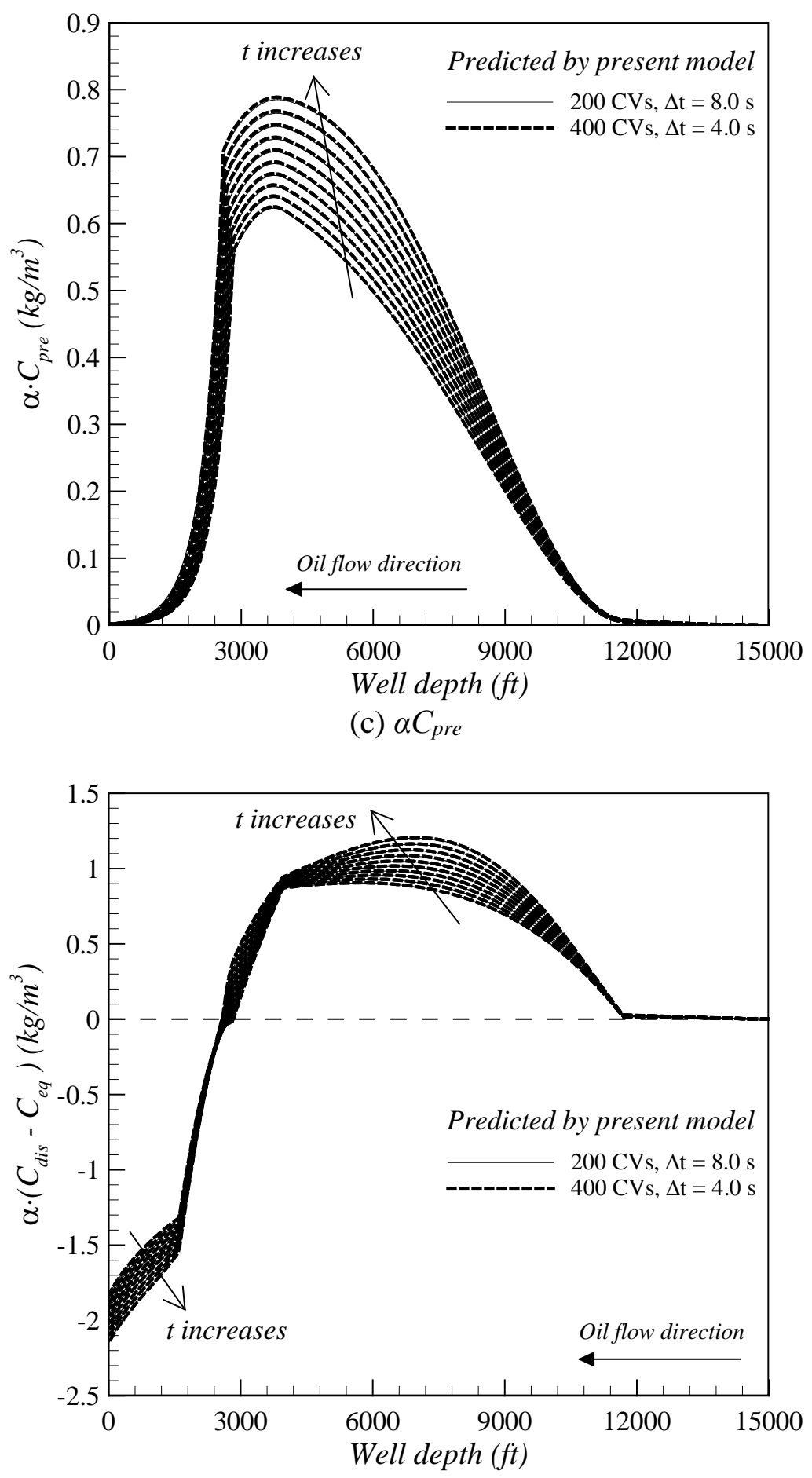

(d) $\alpha\left(C_{d i s}-C_{e q}\right)$

Fig. 11. Predictions for the South Kuwait's Marrat oilwell using the conditions of Kurup et al. (2011) at $t=6,12,18,24,30,36,42,48,54$ and 60 days.

From Fig. 11a, asphaltene deposit starts to form at around $12000 \mathrm{ft}$ well depth and reaches its peak at approximately $4000 \mathrm{ft}$. As the deposit becomes thicker over time, the fluid volume $\alpha$ decreases. From $4000 \mathrm{ft}$ well depth to the surface, asphaltene deposit decreases rapidly and almost diminishes at $1500 \mathrm{ft}$. The deposit profile can be interpreted with reference to the variation of $\alpha\left(C_{d i s}-C_{e q}\right)$ plotted in Fig. 11d, i.e. +ve for precipitation of dissolved asphaltene and -ve for re-dissolution of precipitated asphaltene particles. From $15000 \mathrm{ft}$ to $12000 \mathrm{ft}$ well depth, $\alpha\left(C_{d i s}-C_{e q}\right)$ is almost zero so that asphaltene precipitation is negligible (Fig. 11c). Along the oil flow direction up to $4000 \mathrm{ft}$ well depth, $p$ and $T$ decreases resulting in a decreasing $C_{e q}$ (Fig. 11b), and thus $\alpha\left(C_{d i s}-C_{e q}\right)$ increases. As 
to the surface, $C_{e q}$ increases due to the liberation of some light components. Accordingly, $\alpha\left(C_{d i s}-C_{e q}\right)$ decreases with lesser and lesser precipitated asphaltene particles and forming a thinner deposit layer. Eventually, $\alpha\left(C_{d i s}-C_{e q}\right)$ becomes negative and re-dissolution of some precipitated asphaltene particles happens. . In the meanwhile, the re-dissolution process consumes the amount of precipitated asphaltene particles. With less precipitated asphaltene particles, deposition decreases gradually and finally terminates.

The deposit layer thicknesses predicted using the model developed in this work and that of Kurup et al. (2011) are plotted in Fig. 12 together with the measurement of Kabir and Jamaluddin (2002). As seen in Fig. 12a, a similar asphaltene deposit profile is predicted by the present model. However, the thickest deposit layer predicted by the present model lies at about $3800 \mathrm{ft}$ to the wellhead, while that predicted by Kurup et al. (2011) is at about $5200 \mathrm{ft}$. The deviation in the thickest deposit location originates from the inconsistent BP predictions. As showed in Section 5.2, the developed Thermodynamic Module underpredicts BP for $10.25 \%$ on average. Nonetheless, generally speaking, asphaltene deposition is strongest around BP. Considering that $p$ decreases continuously along the flow direction in wellbore, underprediction of BP causes the maximum deposit point moving downstream. The underprediction of $\mathrm{BP}$ might result from the parameter acquisition process where the input parameters of PR-Peneloux EOS are only tuned to match available UAOP data rather than BP data. In order to account for the underprediction of BP and match the reported deposit cessation point, the predicted deposit layer thickness is translated $1500 \mathrm{ft}$ upstream in Fig.12b. It is clearly observed that the predicted deposit profile then is in good accordance with the measured profile of Kabir and Jamaluddin (2002). Therefore, given a more accurate prediction of $\mathrm{BP}$, the present model could reasonably accurately predict the asphaltene deposit profile.

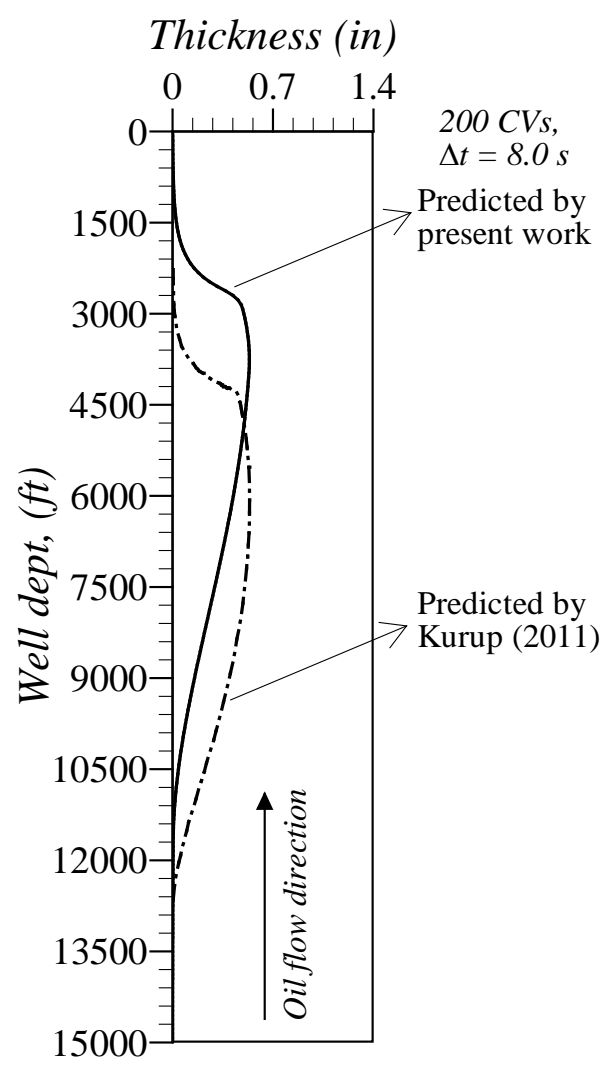

(a) against prediction of Kurup et al. (2011) 


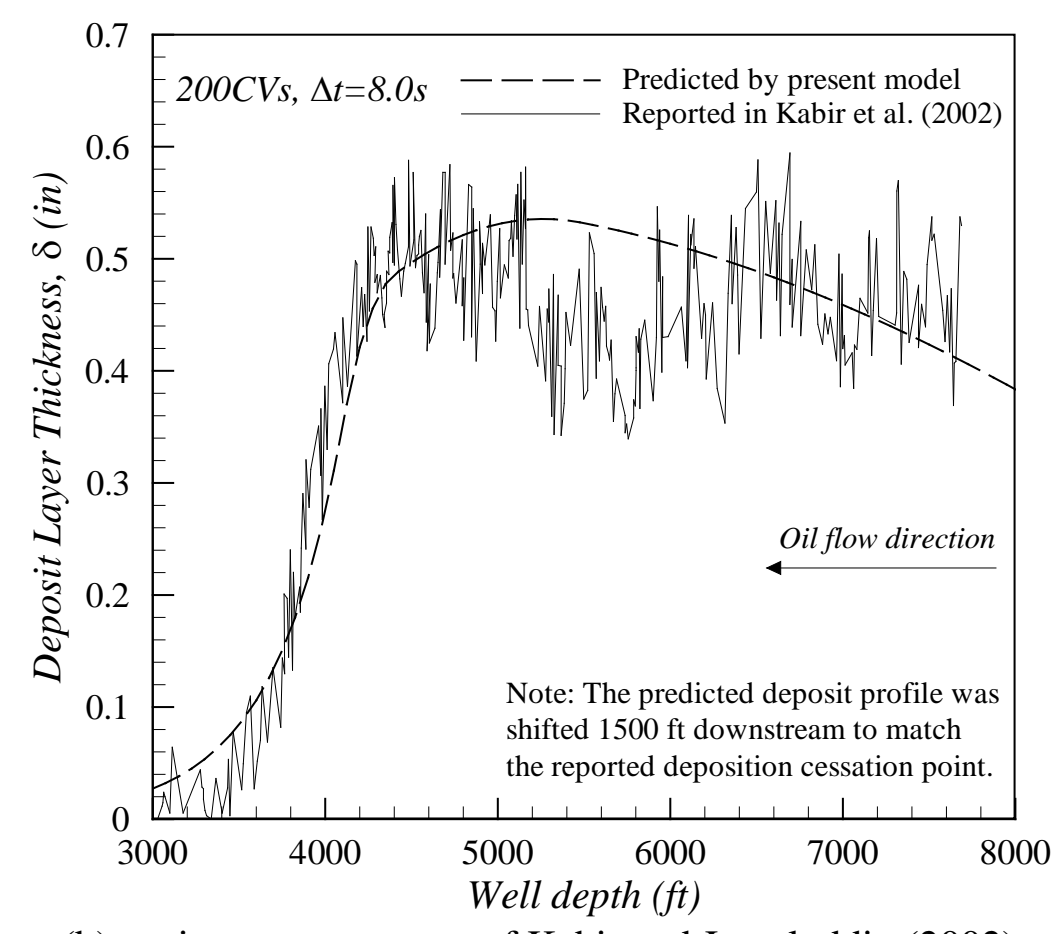

(b) against measurement of Kabir and Jamaluddin (2002)

Fig. 12. Comparison of the predicted deposit profile at $t=60$ days.

\section{Conclusions}

In this article, a numerical model is developed for studying asphaltene deposition problems in wellbores/pipelines. Four indispensable modeling components are considered including Asphaltene Precipitation, Fluid Transport, Particle Transport and Asphaltene Deposition, which are grouped into two sub-modules: a Thermodynamic Module and a Transport Module. These two sub-modules are coupled via a look-up table approach. First, verification and validation of the two modules are conducted. Subsequently, an oilfield asphaltene deposition case is investigated, from which the capability of the presented model to predict the overall asphaltene deposition profile is confirmed. More importantly, the developed integrated model is demonstrated to account for the effect of flow cross-sectional area variation. This variation is important in the sense that as the deposit layer evolves, the velocity and pressure fields, the asphaltene precipitation, and eventually the deposition processes are affected in a fully-coupled manner.

At the current stage, the Transport Module is applicable for single-phase flow. However, when the $p$ and $T$ condition is below bubble point, some light oil components will liberate forming one more vapor phase. In this instance, a two-phase flow model should be incorporated into the Fluid Transport part of the Transport Module. Besides, a more accurate EOS (e.g. PC-SAFT EOS) is desirable to give a better prediction of bubble pressures. These are the future tasks to improve the performance of the model.

\section{ACKNOWLEDGMENTS}

The work is supported by a research Grant from Abu Dhabi National Oil Company (ADNOC) through the Oil Sub-Committee. 


\section{REFERENCES}

Akbarzadeh, K., Alboudwarej, H., Svrcek, W.Y. and Yarranton, H.W., 2005. A Generalized Regular Solution Model for Asphaltene Precipitation from n-alkane Diluted Heavy Oils and Bitumens. Fluid Phase Equilibria, 232(1): 159-170.

Akbarzadeh, K., Eskin, D., Ratulowski, J. and Taylor, S., 2011. Asphaltene Deposition Measurement and Modeling for Flow Assurance of Tubings and Flow Lines. Energy \& Fuels, 26(1): 495-510.

Akbarzadeh, K. et al., 2007. Asphaltenes-Problematic but Rich in Potential. Oilfield Review, 19(2): 22-43.

Al-Qattan, A. et al., 2012. Evaluation of the Effect of Asphaltene Deposition in the Reservoir for the Development of the Magwa Marrat Reservoir, Proceedings of SPE Kuwait International Petroleum Conference and Exhibition, SPE paper, pp. 10-12.

Alboudwarej, H., Akbarzadeh, K., Beck, J., Svrcek, W.Y. and Yarranton, H.W., 2003. Regular Solution Model for Asphaltene Precipitation from Bitumens and Solvents. AIChE Journal, 49(11): 2948-2956.

Alkafeef, S.F., Al-Medhadi, F. and Al-Shammari, A.D., 2003. A Simplified Method to Predict and Prevent Asphaltene Deposition in Oilwell Tubings: Field Case, SPE Annual Technical Conference and Exhibition. Society of Petroleum Engineers.

Arya, A., von Solms, N. and Kontogeorgis, G.M., 2015. Investigation of the Gas Injection Effect on Asphaltene Onset Precipitation Using the Cubic-Plus-Association Equation of State. Energy \& Fuels.

Beal, S.K., 1970. Deposition of Particles in Turbulent Flow on Channel or Pipe Walls. Nuclear Science and Engineering, 40(1): 1-11.

Beggs, D.H. and Brill, J.P., 1973. A Study of Two-Phase Flow in Inclined Pipes. Journal of Petroleum technology, 25(05): 607-617.

Cleaver, J. and Yates, B., 1975. A Sub Layer Model for the Deposition of Particles from a Turbulent Flow. Chemical Engineering Science, 30(8): 983-992.

Colebrook, C.F. et al., 1939. Turbulent Flow in Pipes with Particular Reference to the Transition Region between the Smooth and Rough Pipe Laws. Journal of the Institution of Civil Engineers, 12(8): 393-422.

Creek, J.L., 2005. Freedom of Action in the State of Asphaltenes: Escape from Conventional Wisdom. Energy \& Fuels, 19(4): 1212-1224.

Darabi, H., Shirdel, M., Kalaei, M.H. and Sepehrnoori, K., 2014. Aspects of Modeling Asphaltene Deposition in a Compositional Coupled Wellbore/Reservoir Simulator, SPE Improved Oil Recovery Symposium. Society of Petroleum Engineers.

El-Shobokshy, M. and Ismail, I., 1980. Deposition of Aerosol Particles from Turbulent Flow onto Rough Pipe Wall. Atmospheric Environment (1967), 14(3): 297-304.

Escobedo, J. and Mansoori, G.A., 1995. Asphaltene and Other Heavy-Organic Particle Deposition during Transfer and Production Operations, SPE Annual Technical Conference and Exhibition. Society of Petroleum Engineers.

Escobedo, J. and Mansoori, G.A., 2010. Heavy-organic Particle Deposition from Petroleum Fluid Flow in Oil Wells and Pipelines. Petroleum Science, 7(4): 502-508.

Eskin, D., Ratulowski, J., Akbarzadeh, K. and Pan, S., 2011. Modelling Asphaltene Deposition in Turbulent Pipeline Flows. The Canadian Journal of Chemical Engineering, 89(3): 421-441.

Friedlander, S. and Johnstone, H., 1957. Deposition of Suspended Particles from Turbulent Gas Streams. Industrial \& Engineering Chemistry, 49(7): 1151-1156.

Gonzalez, D.L., Ting, P.D., Hirasaki, G.J. and Chapman, W.G., 2005. Prediction of asphaltene instability under gas injection with the PC-SAFT equation of state. Energy \& Fuels, 19(4): 1230-1234. 
Gonzalez, D.L., Vargas, F.M., Hirasaki, G.J. and Chapman, W.G., 2008. Modeling Study of CO2Induced Asphaltene Precipitation. Energy \& Fuels, 22(2): 757-762.

Guan, Q., 2016. Asphaltene Deposition in One Dimensional Multicomponent Flows, The Petroleum Institute (United Arab Emirates).

Guan, Q. et al., 2018. A unidirectional one-dimensional approach for asphaltene deposition in large length-to-diameter ratios scenarios. Journal of Petroleum Science and Engineering, 166: 857-870.

Guan, Q. et al., 2017. Unidirectional One-Dimensional One-Way Asphaltene Deposition Model for Large Length-to-Diameter Ratios. Journal of Petroleum Science and Engineering (Submitted).

Haghshenasfard, M. and Hooman, K., 2015. CFD Modeling of Asphaltene Deposition Rate from Crude Oil. Journal of Petroleum Science and Engineering, 128: 24-32.

Haskett, C.E. and Tartera, M., 1965. A Practical Solution to the Problem of Asphaltene DepositsHassi Messaoud Field, Algeria. Journal of Petroleum Technology, 17(04): 387-391.

Haugen, K.B., Firoozabadi, A. and Sun, L., 2011. Efficient and Robust Three - Phase Split Computations. AIChE Journal, 57(9): 2555-2565.

Hoteit, H. and Firoozabadi, A., 2006. Simple Phase Stability - Testing Algorithm in the Reduction Method. AIChE journal, 52(8): 2909-2920.

Indo, K. et al., 2009. Asphaltene nanoaggregates measured in a live crude oil by centrifugation. Energy \& Fuels, 23(9): 4460-4469.

Jamaluddin, A., Joshi, N., Iwere, F. and Gurpinar, O., 2002. An Investigation of Asphaltene Instability under Nitrogen Injection, SPE International Petroleum Conference and Exhibition in Mexico. Society of Petroleum Engineers.

Jamaluddin, A. et al., 2000. Laboratory Techniques to Define the Asphaltene Precipitation Envelope, Petroleum Society's Canadian International Petroleum Conference in Calgary, Canada.

Jamialahmadi, M., Soltani, B., Müller-Steinhagen, H. and Rashtchian, D., 2009. Measurement and Prediction of the Rate of Deposition of Flocculated Asphaltene Particles from Oil. International Journal of Heat and Mass Transfer, 52(19): 4624-4634.

Kabir, C., Hasan, A., Lin, D. and Wang, X., 2001. An Approach to Mitigating Wellbore Solids Deposition, SPE Annual Technical Conference and Exhibition. Society of Petroleum Engineers.

Kabir, C. and Jamaluddin, A., 1999. Asphaltene Characterization and Mitigation in South Kuwait's Marrat Reservoir, Middle East Oil Show and Conference. Society of Petroleum Engineers.

Kabir, C. and Jamaluddin, A., 2002. Asphaltene Characterization and Mitigation in South Kuwait's Marrat Reservoir. SPE Production \& Facilities, 17(04): 251-258.

Kokal, S.L. and Sayegh, S.G., 1995. Asphaltenes: The cholesterol of petroleum, Middle East Oil Show. Society of Petroleum Engineers.

Kor, P. and Kharrat, R., 2016a. Modeling of Asphaltene Particle Deposition from Turbulent Oil Flow in Tubing: Model Validation and a Parametric Study. Petroleum.

Kor, P. and Kharrat, R., 2016b. Prediction of the Asphaltene Deposition Profile along a Wellbore during Natural Production from a Reservoir. Energy Sources, Part A: Recovery, Utilization, and Environmental Effects, 38(19): 2837-2844.

Kord, S. and Ayatollahi, S., 2012. Asphaltene Precipitation in Live Crude Oil during Natural Depletion: Experimental Investigation and Modeling. Fluid Phase Equilibria, 336: 63-70.

Kurup, A.S. et al., 2011. Development and Application of an Asphaltene Deposition Tool (ADEPT) for Well Bores. Energy \& Fuels, 25(10): 4506-4516.

Kurup, A.S. et al., 2012. Revisiting Asphaltene Deposition Tool (ADEPT): Field Application. Energy \& Fuels, 26(9): 5702-5710.

Li, Z. and Firoozabadi, A., 2010. Modeling Asphaltene Precipitation by n-alkanes from Heavy Oils and Bitumens Using Cubic-Plus-Association Equation of State. Energy \& Fuels, 24(2): 1106-1113. 
Li, Z. and Firoozabadi, A., 2012. Initialization of phase fractions in Rachford-Rice equations for robust and efficient three-phase split calculation. Fluid Phase Equilibria, 332: 21-27.

Lin, C.-S., Moulton, R. and Putnam, G., 1953. Mass Transfer between Solid Wall and Fluid Streams. Mechanism and Eddy Distribution Relationships in Turbulent Flow. Industrial \& Engineering Chemistry, 45(3): 636-640.

Lindeloff, N., Pedersen, K., Ronningsen, H. and Milter, J., 2004. The Corresponding States Viscosity Model Applied to Heavy Oil Systems. Journal of Canadian Petroleum Technology, 43(9): 47-53.

Michelsen, M.L., 1982a. The isothermal flash problem. Part I. Stability. Fluid Phase Equilibria, 9(1): 1-19.

Michelsen, M.L., 1982b. The isothermal flash problem. Part II. Phase-split calculation. Fluid Phase Equilibria, 9(1): 21-40.

Mirzayi, B., Dehghani, S.A.M. and Chakan, M.B., 2013. Modeling of Asphaltene Deposition in Pipelines. Journal of Petroleum Science and Engineering, 3(2): 15-23.

Moody, L.F., 1944. Friction Factors for Pipe Flow. Trans. ASME, 66(8): 671-684.

Mullins, O.C., 2010. The modified Yen model. Energy \& Fuels, 24(4): 2179-2207.

Nakhli, H. et al., 2011. Monitoring of Asphaltene Precipitation: Experimental and Modeling Study. Journal of Petroleum Science and Engineering, 78(2): 384-395.

Nghiem, L.X. and Coombe, D.A., 1997. Modeling Asphaltene Precipitation during Primary Depletion. SPE Journal, 2(6): 170-176.

Paes, D., Ribeiro, P., Shirdel, M. and Sepehrnoori, K., 2015. Study of Asphaltene Deposition in Wellbores during Turbulent Flow. Journal of Petroleum Science and Engineering, 129: 7787.

Patankar, S.V., 1980. Numerical Heat Transfer and Fluid Flow. Hemisphere Publisher, New York.

Pedersen, K.S., Christensen, P.L. and Shaikh, J.A., 2006. Phase Behavior of Petroleum Reservoir Fluids. CRC Press.

Pedersen, K.S. and Fredenslund, A., 1987. An Improved Corresponding States Model for the Prediction of Oil and Gas Viscosities and Thermal Conductivities. Chemical Engineering Science, 42(1): 182-186.

Pedersen, K.S., Fredenslund, A., Christensen, P.L. and Thomassen, P., 1984. Viscosity of Crude Oils. Chemical Engineering Science, 39(6): 1011-1016.

Péneloux, A., Rauzy, E. and Fréze, R., 1982. A Consistent Correction for Redlich-Kwong-Soave Volumes. Fluid Phase Equilibria, 8(1): 7-23.

Peng, D.-Y. and Robinson, D.B., 1976. A New Two-Constant Equation of State. Industrial \& Engineering Chemistry Fundamentals, 15(1): 59-64.

Rachford Jr, H. and Rice, J., 1952. Procedure for use of electronic digital computers in calculating flash vaporization hydrocarbon equilibrium. Journal of Petroleum Technology, 4(10): 19-3.

Ramirez-Jaramillo, E., Lira-Galeana, C. and Manero, O., 2006. Modeling Asphaltene Deposition in Production Pipelines. Energy \& Fuels, 20(3): 1184-1196.

Robinson, D.B. and Peng, D.-Y., 1978. The Characterization of the Heptanes and Heavier Fractions for the GPA Peng-Robinson Programs. Gas Processors Association.

Shirdel, M., Paes, D., Ribeiro, P. and Sepehrnoori, K., 2012. Evaluation and Comparison of Different Models for Asphaltene Particle Deposition in Flow Streams. Journal of Petroleum Science and Engineering, 84: 57-71.

Soulgani, B.S., Rashtchian, D., Tohidi, B. and Jamialahmadi, M., 2009. Integrated Modelling Methods for Asphaltene Deposition in Wellstring. Journal of the Japan Petroleum Institute, 52(6): 322-331322.

Vargas, F.M., Creek, J.L. and Chapman, W.G., 2010. On the Development of an Asphaltene Deposition Simulator. Energy \& Fuels, 24(4): 2294-2299.

Vargas, F.M. et al., 2014. On the development of an enhanced method to predict asphaltene precipitation, Offshore Technology Conference. Offshore Technology Conference. 
1 Versteeg, H.K. and Malalasekera, W., 2007. An Introduction to Computational Fluid Dynamics: 2 The Finite Volume Method. Prentice Education Limited, England.

3 Wilson, G.M., 1969. A modified Redlich-Kwong equation of state, application to general physical 4 data calculations, 65th National AIChE Meeting, Cleveland, OH.

5 Zhang, X., Pedrosa, N. and Moorwood, T., 2012. Modeling Asphaltene Phase Behavior: 6 Comparison of Methods for Flow Assurance Studies. Energy \& Fuels, 26(5): 2611-2620. 


\section{APPENDIX}

\section{A. Reservoir Fluid Viscosity Calculation}

The method adopted in this work to calculate the dynamic viscosity of a mixture (reservoir fluid) refers to the work of Pedersen et al. (2006). The basic idea is to deduce the mixture viscosity at the specified $T$ and $P$ from the viscosity of a reference component at a reference temperature $\left(T_{\text {ref }}\right)$ and pressure $\left(P_{r e f}\right)$. Methane, whose viscosity has been calculated at a wide range of $T$ and $P$ in existing studies, serves as the reference component. The reference condition $T_{\text {ref }}$ and $P_{\text {ref }}$ are defined as

$$
\begin{aligned}
& T_{r e f}=\left(T T_{c, C_{1}} / T_{c, \text { mix }}\right)\left(\alpha_{C_{1}} / \alpha_{\text {mix }}\right) \\
& P_{\text {ref }}=\left(P P_{c, C_{1}} / P_{c, \text { mix }}\right)\left(\alpha_{C_{1}} / \alpha_{\text {mix }}\right)
\end{aligned}
$$

10

Besides, $\rho_{r}$ in eq. (A.3) is

$$
M_{\text {mix }}=1.304 \times 10^{-4}\left(M_{w}^{2.303}-M_{n}^{2.303}\right)+M_{n}
$$

where $M_{w}$ and $M_{n}$ are respectively the weight average and number average molecular weights defined as

$$
\begin{gathered}
M_{w}=\sum_{i=1}^{N} z_{i} M_{i}^{2} / \sum_{i=1}^{N} z_{i} M_{i} \\
M_{n}=\sum_{i=1}^{N} z_{i} M_{i}
\end{gathered}
$$
where $\rho_{r}$ is reduced density, and $M_{\text {mix }}$ is mixture molecular weight. Note that eq. (A.3) can also be used to calculate $\alpha_{C_{1}}$ through replacing $M_{\text {mix }}$ by the molecular weight of methane. In eq. (A.3), $M_{\text {mix }}$ is determined from

$$
\begin{aligned}
& T_{c, \text { mix }}= \frac{\sum_{i=1}^{N} \sum_{j=1}^{N} x_{i} X_{j}\left[\left(T_{c i} / P_{c i}\right)^{1 / 3}+\left(T_{c j} / P_{c j}\right)^{1 / 3}\right] \sqrt{T_{c i} T_{c j}}}{\sum_{i=1}^{N} \sum_{j=1}^{N} x_{i} X_{j}\left[\left(T_{c i} / P_{c i}\right)^{1 / 3}+\left(T_{c j} / P_{c j}\right)^{1 / 3}\right]^{\beta}} \\
& P_{c, \text { mix }}=\frac{8 \sum_{i=1}^{N} \sum_{j=1}^{N} x_{i} X_{j}\left[\left(T_{c i} / P_{c i}\right)^{1 / 3}+\left(T_{c j} / P_{c j}\right)^{1 / 3}\right]^{\beta} \sqrt{T_{c i} T_{c j}}}{\left(\sum_{i=1}^{N} \sum_{j=1}^{N} x_{i} X_{j}\left[\left(T_{c i} / P_{c i}\right)^{1 / 3}+\left(T_{c j} / P_{c j}\right)^{1 / 3}\right]^{3}\right)^{2}}
\end{aligned}
$$

$$
\rho_{r}=\rho_{C_{1}}\left(\frac{T T_{c, C_{1}}}{T_{c, \text { mix }}}, \frac{P P_{c, C_{1}}}{P_{c, \text { mix }}}\right) / 0.16284
$$

21 where $\rho_{C_{1}}$ is the density of methane at the temperature of $T T_{c, C_{1}} / T_{c, \text { mix }}$ and pressure of $P P_{c, C_{1}} / P_{c, \text { mix }}$. 22 It can be computed by solving

$$
P=\sum_{n=1}^{9} a_{n}(T) \rho^{n}+\sum_{n=10}^{15} a_{n}(T) \rho^{2 n-17} e^{-\gamma \rho^{2}}
$$


where $\mu_{C_{1}}$ is the viscosity of methane at $T_{\text {ref }}$ and $P_{\text {ref }}$. To determine the viscosity of methane at a temperature $T$ and pressure $P$, eq. (A.9) is applicable.

$$
\mu_{C_{1}}(P, T)=\mu_{0}(T)+\mu_{1}(T)+F_{1} \Delta \mu^{\prime}(P, T)+F_{2} \Delta \mu^{\prime \prime}(P, T)
$$

10 where $\mu_{0}, \mu_{1}, \Delta \mu^{\prime}$ and $\Delta \mu^{\prime}$ are

$$
\begin{gathered}
\mu_{0}(T)=\sum_{n=1}^{9} G V_{n} T^{(n-4) / 3} \\
\mu_{1}(T)=A+B\left(C-\ln \frac{T}{F}\right)^{2} \\
\Delta \mu^{\prime}(P, T)=\exp \left(j_{1}+\frac{j_{4}}{T}\right)\left[\exp \left(\rho^{0.1}\left(j_{2}+\frac{j_{3}}{T^{3 / 2}}\right)+\theta \rho^{0.5}\left(j_{5}+\frac{j_{6}}{T}+\frac{j_{7}}{T^{2}}\right)\right)-1.0\right] \\
\Delta \mu^{\prime \prime}(P, T)=\exp \left(k_{1}+\frac{k_{4}}{T}\right)\left[\exp \left(\rho^{0.1}\left(k_{2}+\frac{k_{3}}{T^{3 / 2}}\right)+\theta \rho^{0.5}\left(k_{5}+\frac{k_{6}}{T}+\frac{k_{7}}{T^{2}}\right)\right)-1.0\right]
\end{gathered}
$$

11 Note that $G V_{1}$ to $G V_{9}$ in eq. (A.10a); $A, B, C$ and $F$ in eq. (A.10b); $j_{1}$ to $j_{7}$ in eq. (A.10c); and $k_{1}$ 12 to $k_{7}$ in eq. (A.10d) are all known constants.

13

Besides, $F_{1}$ and $F_{2}$ in eq. (A.9) are

$$
\begin{aligned}
& F_{1}=\frac{1+H T A N}{2} \\
& F_{2}=\frac{1-H T A N}{2}
\end{aligned}
$$

where HTAN is defined as

$$
H T A N=\frac{\exp (T-91)-\exp (91-T)}{\exp (T-91)+\exp (91-T)}
$$

\section{A.2 Corresponding States Method for Heavy Oils Consideration}

When $T_{r e f}<50 \mathrm{~K}$, the mixture viscosity at the specified $T$ and $P$ is calculated by

$$
\mu_{\text {mix }}=\mu_{C_{1}} \exp \left(0.00384 \frac{P^{0.8226}-1}{0.8226}\right)
$$

19 with $\mu_{C_{1}}$ determined from

$$
\log _{10} \mu_{C_{1}}=\left\{\begin{array}{l}
-0.07995+0.01101 M-\frac{371.8}{T}+\frac{6.215 M}{T}, \text { for } T>564.49 K \\
-0.07995-0.01101 M-\frac{371.8}{T}+\frac{6.215 M}{T}, \text { for } T \leq 564.49 K
\end{array}\right.
$$


1 The term $M$ in eq. (A.14) is

$$
M= \begin{cases}M_{n}\left(1.5 / F_{3}\right)^{F_{4}} & , \text { for } M_{w} / M_{n} \leq 1.5 \\ M_{n}\left(M_{w} / F_{3} M_{n}\right)^{F_{4}} & , \text { for } M_{w} / M_{n}>1.5\end{cases}
$$

2 where $F_{3}$ and $F_{4}$ are calculated by

$$
\begin{gathered}
F_{3}=0.2252\left(T / M_{n}\right)+0.9738 \\
F_{4}=0.5354 F_{3}-0.1170
\end{gathered}
$$

3

\section{A.3 Interpolation of the abovementioned Two Methods}

5 When $50 \mathrm{~K} \leq T_{\text {ref }} \leq 75 \mathrm{~K}$, the mixture viscosity at a specified $T$ and $P$ is calculated by interpolating

6 the results of the above-mentioned two methods as

$$
\mu_{\text {mix }}=F_{1} \mu_{C S P}+F_{2} \mu_{\text {Heavy }}
$$

7 where $F_{1}$ and $F_{2}$ are determined in Eq. (A.11). However, in this case, HTAN is defined as

$$
H T A N=\frac{\exp (T-70)-\exp (70-T)}{\exp (T-70)+\exp (70-T)}
$$

8

9 


\section{B. Multicomponent Multiphase Flash Calculation Program}

During oil transportation in wellbores/pipelines, three phases possibly exist in oil: asphaltene-lean liquid phase $\left(\mathrm{L}_{1}\right)$, asphaltene-rich liquid phase $\left(\mathrm{L}_{2}\right)$, and vapor phase $(\mathrm{V})$. Under a given $p$ and $T$ condition, the number of potential phases at equilibrium is not known in advance which usually hinders the multicomponent multiphase flash calculation. To circumvent this problem, a sequential method is adopted. This method consists of a stability test part and a phase split (or referred to as phase equilibrium calculation) part. To begin with, the oil is assumed as a single-phase fluid at the specified $p$ and $T$. Then a stability test is performed to check whether this single-phase fluid is stable. If it is unstable, then the oil is assumed in a two-phase state. Subsequently, a two-phase equilibrium calculation is performed splitting the oil into two phases. Any one of these two phases is tested again to justify the stability of the oil. If the second stability analysis indicates the oil is unstable again in a two-phase state, then a three-phase situation is considered followed by a threephase equilibrium calculation to determine the final compositions of all these three phases at equilibrium. The flow chart of this flash calculation program is shown in Fig. B.1.

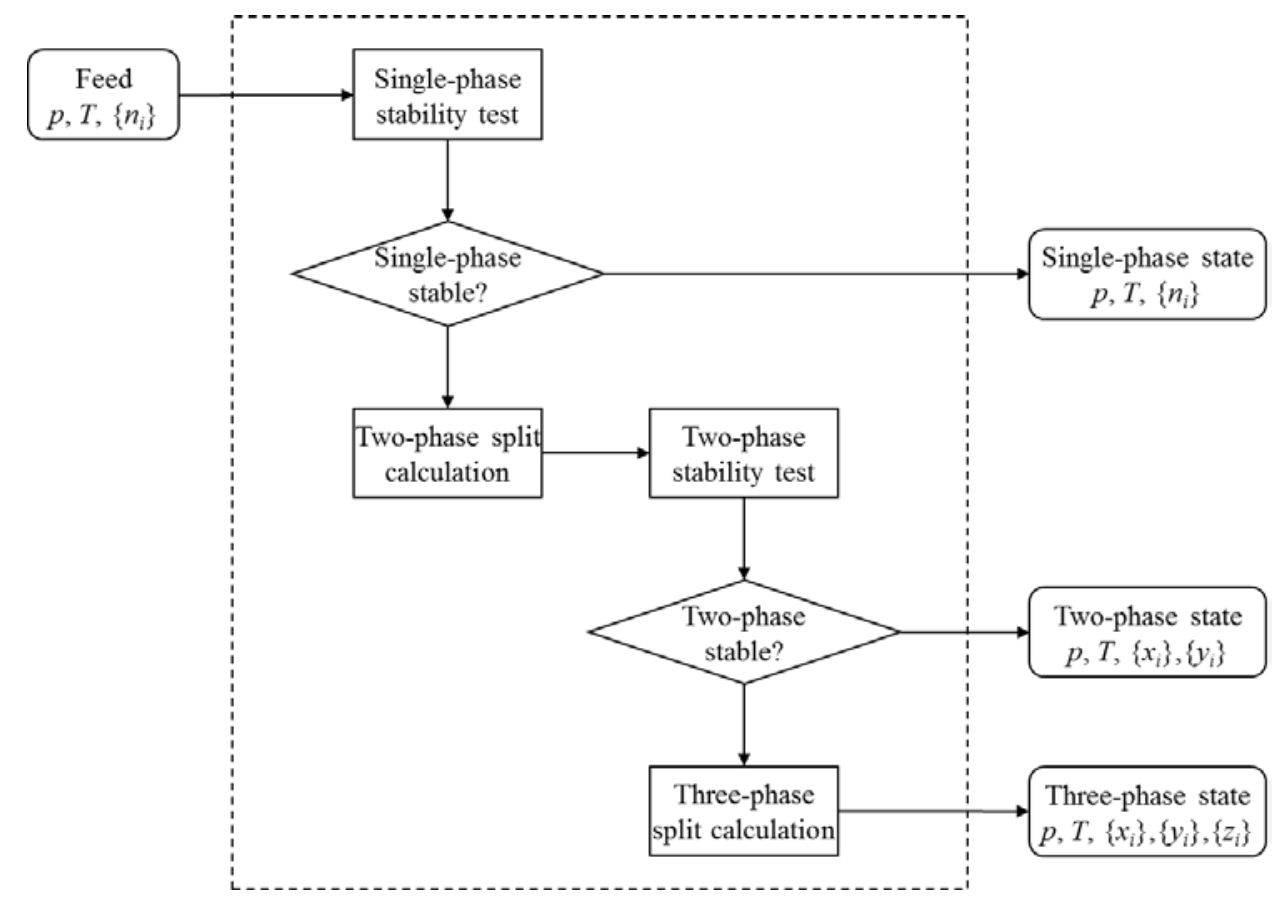

Fig. B.1. Flow chart of the multicomponent multiphase flash calculation program

\section{B.1 Stability Test Program}

The flow chart of the stability test program is shown in Fig. B.2, which is developed according to the method of Michelsen (1982a) who successfully demonstrated that a mixture is stable only when the tangent-plane-distance (TPD) function is nonnegative for all trial compositions (eq. B.1).

$$
T P D(\vec{\xi})=1+\sum_{i=1}^{N_{c}} \xi_{i}\left[\ln \varphi_{i}(T, P, \vec{\xi})+\ln \xi_{i}-h_{i}-1\right] \geq 0 \quad \forall \xi_{i} \geq 0
$$

where $\xi_{i}=x_{i} e^{-k}, x_{i}=\xi_{i} / \sum_{j=1}^{N_{c}} \xi_{j}$, and $h_{i}=\ln \varphi_{i}(T, P, \vec{z})+\ln z_{i}$. By introducing an iteration variable $\alpha_{i}=2\left(\xi_{i}\right)^{0.5}$, the stability analysis problem is converted to an unconstrained minimization problem. In this work, eq. (B.1) is only checked at stationary points of the TPD function instead of searching its global minimal value. To locate the stationary points of this TPD function, a quasi-newton method called Broyden-Fletcher-Golfarb-Shanno (BFGS) update (Hoteit and Firoozabadi, 2006) is used. The basic idea of this method is to use an approximate Hessian matrix $B^{k+1}$ with the gradients of the TPD function $G\left(\alpha^{k}\right)$ and $G\left(\alpha^{k+1}\right)$ to update the iteration variable from $\alpha^{k}$ to $\alpha^{k+1}$ as

$$
B^{k+1} s^{k}=g^{k} \text {, with } s^{k}=\alpha^{k+1}-\alpha^{k} \text { and } g^{k}=G\left(\alpha^{k+1}\right)-G\left(\alpha^{k}\right)
$$


1 The Hessian approximation $B^{k+1}$ is calculated from

$$
B^{k+1}=B^{k}-\frac{B^{k} s^{k}\left(s^{k}\right)^{T} B^{k}}{\left(s^{k}\right)^{T} B^{k} s^{k}}+\frac{g^{k}\left(g^{k}\right)^{T}}{\left(g^{k}\right)^{T} s^{k}}
$$

2 and the $i$-th component of $G\left(\alpha^{k}\right)$ is determined from

$$
G\left(\alpha_{i}^{k}\right)=\frac{\partial}{\partial \alpha_{i}^{k}} T P D\left(\vec{\xi}^{k}\right)=\left\{\sqrt{\xi_{i}}\left[\ln \varphi_{i}(T, P, \vec{\xi})+\ln \xi_{i}-h_{i}\right]\right\}^{k}
$$

3 Finally, the updating equation is derived and shown as

$$
\alpha^{k+1}-\alpha^{k}=\widetilde{G}^{k}
$$

4 where $\tilde{G}^{k}$ is found by

$$
\tilde{G}^{k}=-\left[G\left(\alpha^{k}\right)+\frac{s^{k}}{\left(s^{k}\right)^{T} g^{k}}\left(\left(s^{k}-g^{k}\right)^{T} G\left(\alpha^{k}\right)+\frac{\left(g^{k}\right)^{T} g^{k}\left(s^{k}\right)^{T} G\left(\alpha^{k}\right)}{\left(s^{k}\right)^{T} g^{k}}\right)-\frac{\left(s^{k}\right)^{T} G\left(\alpha^{k}\right) g^{k}}{\left(s^{k}\right)^{T} g^{k}}\right]
$$

Prior to the BFGS update, the initial trial composition should be provided. The performance of the stationary point approach relies heavily on the quality of initial guess. Considering an improper initial trial composition, a trivial solution will be found or even no convergence can be achieved. $\mathrm{Li}$ and Firoozabadi (2012) suggested the use of multiple initial guesses to circumvent this deficiency. The sequential initial estimates are acquired by $x_{i}=z_{i} K_{i}^{\text {initial }}$, where $K_{i}^{\text {initial }}$ is

$$
\begin{aligned}
& K_{i}^{\text {initial }}=\left[K_{i}^{\text {Wilson }}, 1 / K_{i}^{\text {Wilson }}, \sqrt[3]{K_{i}^{\text {Wilson }}}, 1 / \sqrt[3]{K_{i}^{\text {Wilson }}},\right. \\
& \left\{\begin{array}{l}
K_{i}^{\text {pure }}=0.9 / z_{i} \\
K_{j}^{\text {pure }}=0.9 /\left(N_{c}-1\right) / z_{j}(j \neq i)
\end{array}\left(i=1 \text { to } N_{c}\right)\right]
\end{aligned}
$$

with $K^{\text {Wilson }}$ denoting the Wilson's correlation (Wilson, 1969) as

$$
K_{i}^{\text {Wilson }}=\frac{p_{c i}}{p} \exp \left(5.37\left(1+\omega_{i}\right)\left(1-\frac{T_{c i}}{T}\right)\right)
$$

The last term in eq. (B.7a) represents the situation having a pure substance in the mixture. In this case, the pure substance is assumed taking up $90 \mathrm{~mol} \%$ of the mixture, and the other components sharing evenly the remaining $10 \mathrm{~mol} \%$. Besides, Michelsen (1982a) gave another guess as shown in eq. (B.8) which is effective for a range of systems.

$$
x_{i}^{\text {trial }}=\exp \left(\ln \varphi_{i}(T, P, \bar{z})+\ln z_{i}\right)
$$

In the current work, these $\left(N_{c}+5\right)$ sets of initial trial composition (eq. B.7-8) are all used. If a trivial solution is found or there is no convergence can be attained, the program will proceed to the next set of initial guess and repeat the BFGS update. Besides if the current used initial trial indicates a stable mixture, then this program also goes to choose the next set of initial guess and repeat the BFGS update until an unstable solution is sought. Provided that no unstable solution for all the $\left(N_{c}+5\right)$ sets of initial guesses can be found, then the mixture is concluded stable.

The BFGS update is terminated when (1) the number of iteration (iter) exceeds the prescribed maximum iteration (iter_max), i.e. not converged; (2) eq. (B.9) is satisfied, i.e. a converged solution is found.

$$
\left\|\alpha^{k+1}-\alpha^{k}\right\|_{2}<e p s \_c o n
$$

If eq. (B.10) is met, the converged solution is a non-trivial solution.

$$
\sqrt{\sum_{i=1}^{N_{c}}\left(x_{i}-z_{i}\right)^{2}}>\text { eps_triv }
$$

Then the TPD function is evaluated to check whether eq. (B.11) is satisfied. If yes, the converged non-trivial solution is determined unstable. 


$$
\operatorname{TPD}(\vec{\xi})=1+\sum_{i=1}^{N_{c}} \xi_{i}\left[\ln \varphi_{i}(T, P, \vec{\xi})+\ln \xi_{i}-h_{i}-1\right]<e p s \_s t a
$$

1 In this work, the tolerances and maximum iteration is eps_con $=10^{-12}$, eps_triv $=10^{-5}$, eps_sta $=10^{-}$ 210 and iter_max $=2000$.

3

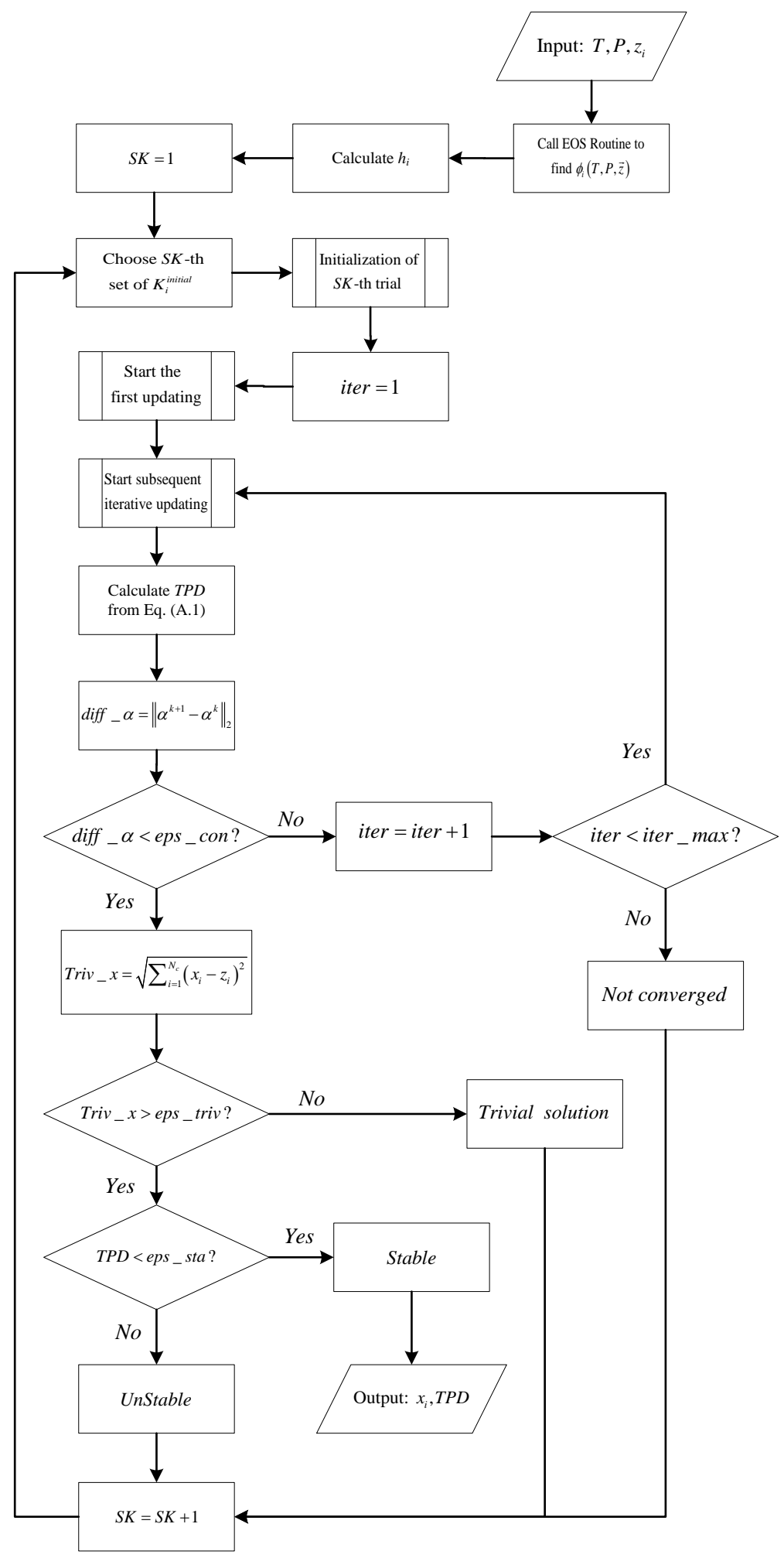

(a) main routine 


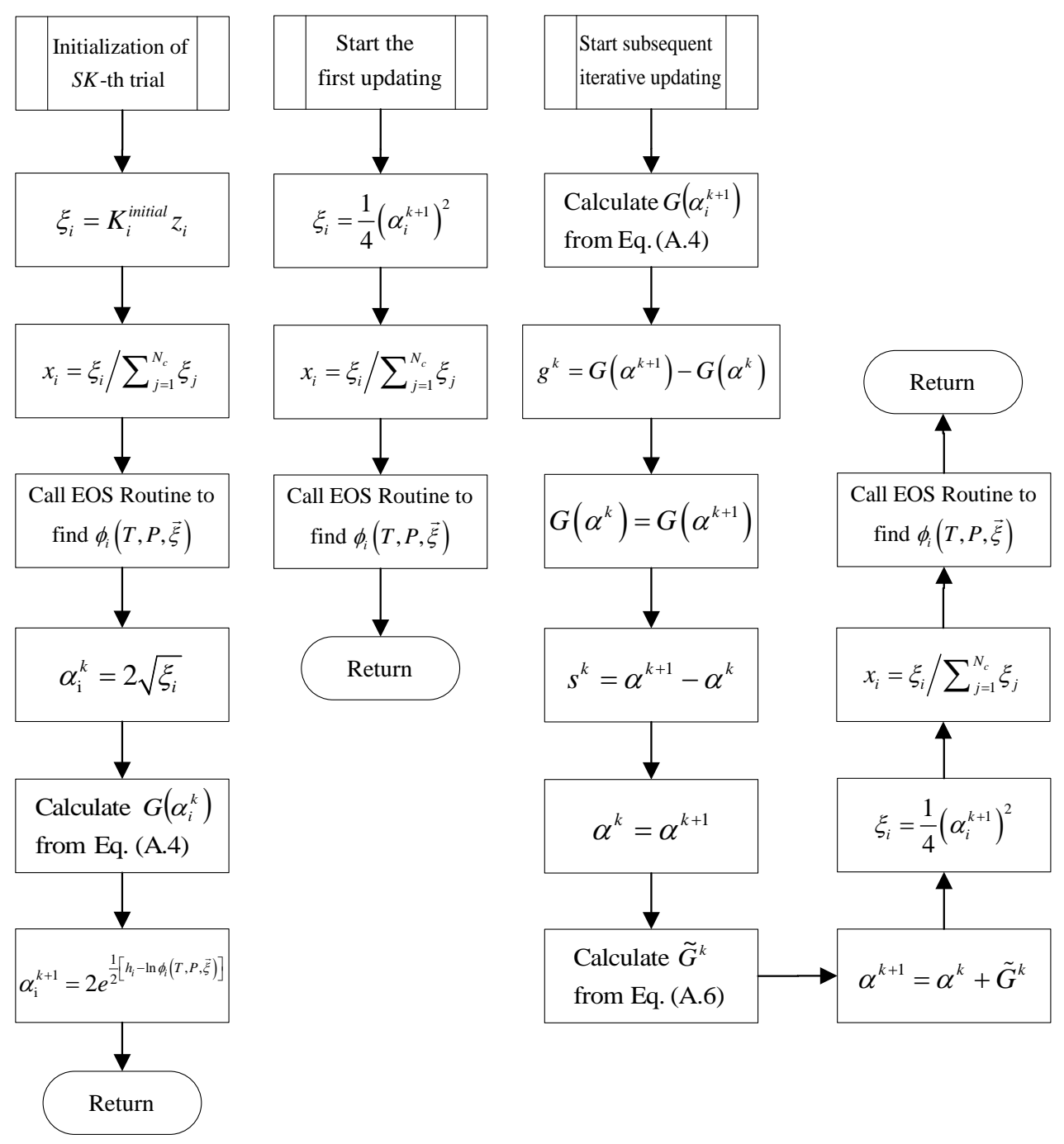

(b) three subroutines

Fig. B.2. Flow chart of the developed stability test program

\section{B.2 Phase Split Program}

Once the stability test indicates the mixture is unstable, either a two-phase or a three-phase split calculation is performed to determine the compositions in all possible phases. The principles of the two-phase split and three-phase split calculations are the same: at equilibrium, the fugacities of each component in existing phases are equal.

\section{B.2.1 Two-phase Split Calculation}

Assume there are two existing phases (phase 1 and phase 2) in a mixture of $N_{c}$ components under a specific $p$ and $T$ condition. The feed composition is $z_{i}$ (for $i=1$ to $N_{c}$ ). The mole fractions of the component $i$ in the phase 1 and phase 2 are denoted respectively by $x_{i}$ and $y_{i}$. Let the nondimensional mole number of the phase 2 be $\beta$. According to the material balance of each component in the mixture,

$$
z_{i}=(1-\beta) x_{i}+\beta y_{i}, \quad i=1,2, \ldots, N_{c}
$$

Besides, the mole fractions of all components in these two phases satisfy:

$$
\sum_{i=1}^{N_{c}}\left(y_{i}-x_{i}\right)=0 \text {, since } \sum_{i=1}^{N_{c}} x_{i}=1 \text { and } \sum_{i=1}^{N_{c}} y_{i}=1
$$

By introducing the equilibrium ratio as $K_{i}=y_{i} / x_{i}, x_{i}$ and $y_{i}$ can be solved from 


$$
\begin{gathered}
x_{i}=\frac{z_{i}}{1+\beta\left(K_{i}-1\right)}, \quad i=1,2, \ldots, N_{c} \\
y_{i}=\frac{z_{i} K_{i}}{1+\beta\left(K_{i}-1\right)}, \quad i=1,2, \ldots, N_{c}
\end{gathered}
$$

1 Substituting eq. (B.14) into eq. (B.13) yields the Rachford-Rice equation (Rachford Jr and Rice, 2 1952):

$$
f(\beta)=\sum_{i=1}^{N_{c}} \frac{z_{i}\left(K_{i}-1\right)}{1+\left(K_{i}-1\right) \beta}=0
$$

Once $K_{i}$ at equilibrium state are determined, then $\beta$ can be solved from the Rachford-Rice equation using either a bisection method or a Newton-Raphson method. Finally, $x_{i}$ and $y_{i}$ are readily solved according to eq. (B.14). However, the values of $K_{i}$ at equilibrium state at the specified $p$ and $T$ are not known in advance. An iterative process is engaged where $K_{i}$ are updated successively according to the calculated fugacities of two phases. The updating procedure is expressed as

$$
K_{i}^{\text {new }}=K_{i}^{\text {old }} \frac{\hat{f}_{i}^{1}}{\hat{f}_{i}^{2}}=\frac{y_{i} \hat{f}_{i}^{1}}{x_{i} \hat{f}_{i}^{2}}, \text { for } i=1, \ldots, N_{c}
$$

where $\hat{f}_{i}^{1}$ and $\hat{f}_{i}^{2}$ represent respectively the fugacities of component $i$ in the phase 1 and phase 2 . These fugacities can be calculated using an EOS by

$$
\begin{aligned}
& \hat{f}_{i}^{1}=\phi_{i x} x_{i} p, \text { for } i=1, \ldots, N_{c} \\
& \hat{f}_{i}^{2}=\phi_{i x} y_{i} p, \text { for } i=1, \ldots, N_{c}
\end{aligned}
$$

As aforementioned, the equilibrium condition for a two-phase mixture is:

$$
\hat{f}_{i}^{1}=\hat{f}_{i}^{2}, \text { for } i=1, \ldots, N_{c}
$$

It is clearly seen that when the equilibrium condition is reached, the updating equation is identical to the definition of $K_{i}$. As to the initial values of $K_{i}$, the Wilson's correlation (eq. B.7b) can be adopted. Besides, the result of the previous stability test can also be used. According to the trials conducted, it is found that using the result of the previous stability test as the initial values of $K_{i}$ is more appropriate when $p$ and $T$ is above bubble point, whereas, the Wilson's correlation is better below bubble point. The flow chart of the two-phase split calculation program is given in Fig. B.3. In this program, an in-house subprogram is developed to solve the well-known Rachford-Rice equation (Fig. B.4). 


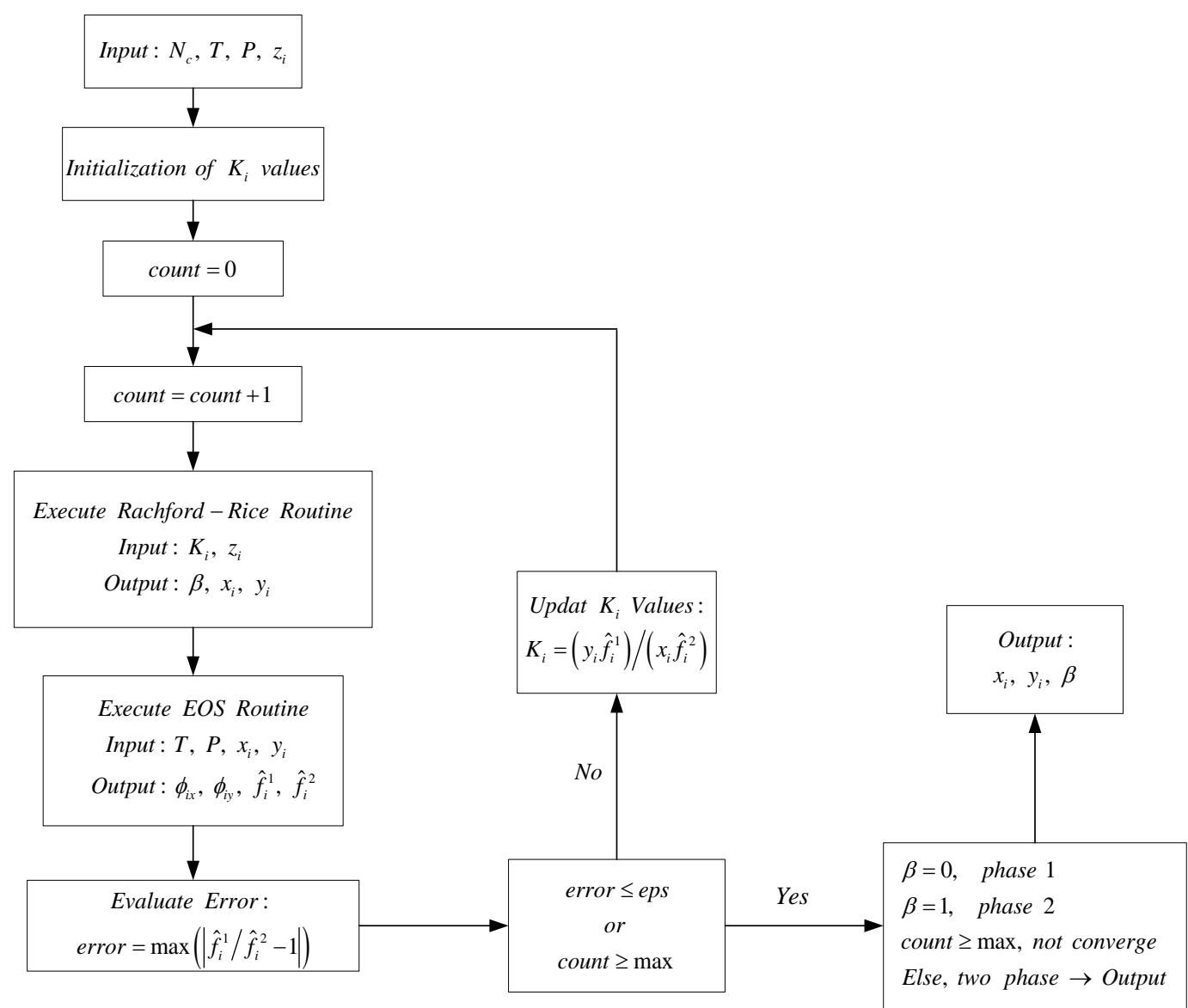

Fig. B.3. Flow chart of the two-phase split calculation program

Input : $K_{i}, z_{i}$
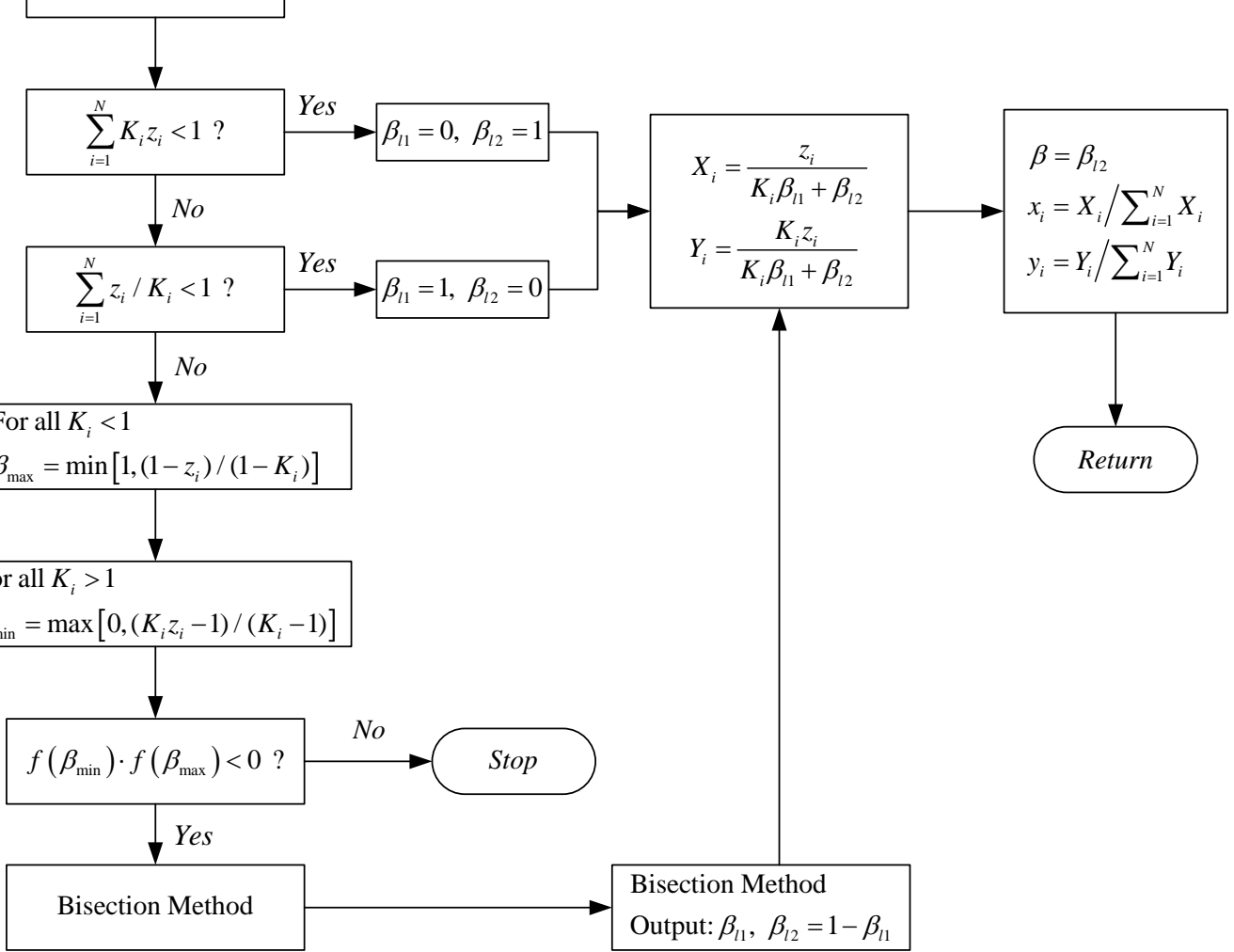

Fig. B.4. Flow chart of the 'Rachford-Rice Routine' 
B.2.2 Three-phase Split Calculation

The three-phase split calculation is similar to the two-phase split calculation. By choosing the $\mathrm{L}_{1}$ phase as a reference phase, two equilibrium ratios are introduced as

$$
K_{y i}=y_{i} / x_{i} \text { and } K_{z i}=z_{i} / x_{i}
$$

4 Following the similar derivation steps in the previous two-phase split calculation, two Rachford-

5 Rice equations are acquired as:

$$
\begin{gathered}
R R_{y}=\sum_{i=1}^{N_{c}} \frac{n_{i}\left(K_{y i}-1\right)}{1+\beta_{2}\left(K_{y i}-1\right)+\beta_{3}\left(K_{z i}-1\right)}=0 \\
R R_{z}=\sum_{i=1}^{N_{c}} \frac{n_{i}\left(K_{z i}-1\right)}{1+\beta_{2}\left(K_{y i}-1\right)+\beta_{3}\left(K_{z i}-1\right)}=0
\end{gathered}
$$

6 The updating procedure of $K_{y i}$ and $K_{z i}$ is expressed by

$$
\begin{aligned}
& K_{y i}^{\text {new }}=K_{y i}^{\text {old }} \frac{\hat{f}_{i}^{1}}{\hat{f}_{i}^{2}}=\frac{y_{i} \hat{f}_{i}^{1}}{x_{i} \hat{f}_{i}^{2}}, \text { for } i=1, \ldots, N_{c} \\
& K_{z i}^{\text {new }}=K_{z i}^{\text {old }} \frac{\hat{f}_{i}^{1}}{\hat{f}_{i}^{3}}=\frac{z_{i} \hat{f}_{i}^{1}}{x_{i} \hat{f}_{i}^{3}}, \text { for } i=1, \ldots, N_{c}
\end{aligned}
$$

$7 \quad$ As long as $K_{y i}$ and $K_{z i}$ are determined through successive iteration, then $\beta_{2}$ and $\beta_{3}$ at equilibrium are 8 solved from these two Rachford-Rice equations (eq. B.20) by means of a two-dimensional bisection 9 method (Haugen et al., 2011). Then, $x_{i}, y_{i}$, and $z_{i}$ are readily obtained from

$$
\begin{aligned}
x_{i} & =\frac{n_{i}}{1+\beta_{2}\left(K_{y i}-1\right)+\beta_{3}\left(K_{z i}-1\right)} \\
y_{i} & =\frac{n_{i} K_{y i}}{1+\beta_{2}\left(K_{y i}-1\right)+\beta_{3}\left(K_{z i}-1\right)} \\
z_{i} & =\frac{n_{i} K_{z i}}{1+\beta_{2}\left(K_{y i}-1\right)+\beta_{3}\left(K_{z i}-1\right)}
\end{aligned}
$$


Table C.1. Compositions (mol\%) of the oils used in this study.

\begin{tabular}{cccc}
\hline Component & $\begin{array}{c}\text { Oil 1 } \\
\text { (Jamaluddin et } \\
\text { al., 2000) }\end{array}$ & $\begin{array}{c}\text { Oil 2 } \\
\text { (Jamaluddin et } \\
\text { al., 2002) }\end{array}$ & $\begin{array}{c}\text { Oil 3 } \\
\text { (Kabir and } \\
\text { Jamaluddin, } \\
1999)\end{array}$ \\
\hline $\mathrm{N}_{2}$ & 0.48 & 0.49 & 0.088 \\
$\mathrm{CO}_{2}$ & 0.92 & 11.37 & 0.048 \\
$\mathrm{H}_{2} \mathrm{~S}$ & 0.00 & 3.22 & 1.022 \\
$\mathrm{C}_{1}$ & 43.43 & 27.36 & 42.420 \\
$\mathrm{C}_{2}$ & 11.02 & 9.41 & 10.800 \\
$\mathrm{C}_{3}$ & 6.55 & 6.70 & 6.918 \\
$\mathrm{iC}_{4}$ & 0.79 & 0.81 & 0.957 \\
$\mathrm{nC}_{4}$ & 3.70 & 3.17 & 3.518 \\
$\mathrm{iC}_{5}$ & 1.28 & 1.22 & 1.213 \\
$\mathrm{nC}_{5}$ & 2.25 & 1.98 & 2.086 \\
$\mathrm{C}_{6}$ & 2.70 & 2.49 & $2.860^{a}$ \\
$\mathrm{C}_{7+}$ & 26.88 & 31.79 & 28.070 \\
$\mathrm{C}_{7+} \mathrm{MW}_{7+}$ (g/mol) & 228.10 & 248.30 & 216.48 \\
$\mathrm{C}_{7+}$ density & & & \\
$\left(\mathrm{g} / \mathrm{cm}^{3}\right.$ ) at 1.01 & 0.865 & 0.877 & 0.840 \\
bar and 288.15 K & & & \\
${ }^{a}$ The mole fraction of $\mathrm{C}_{6}$ is taken from Al-Qattan et al. (2012).
\end{tabular}

Table C.2. Nonzero BIPs $\left(k_{i j}\right)$ employed in this study ${ }^{a}$.

\begin{tabular}{ccccc}
\hline & $\mathrm{N}_{2}$ & $\mathrm{CO}_{2}$ & $\mathrm{H}_{2} \mathrm{~S}$ & $\mathrm{C}_{1}-\mathrm{C}_{9}$ \\
\hline $\mathrm{CO}_{2}$ & -0.0170 & - & - & - \\
$\mathrm{H}_{2} \mathrm{~S}$ & 0.1767 & 0.0974 & - & - \\
$\mathrm{C}_{1}$ & 0.0311 & 0.1200 & 0.0800 & - \\
$\mathrm{C}_{2}$ & 0.0515 & 0.1200 & 0.0833 & - \\
$\mathrm{C}_{3}$ & 0.0852 & 0.1200 & 0.0878 & - \\
$\mathrm{iC}_{4}$ & 0.1033 & 0.1200 & 0.0474 & - \\
$\mathrm{nC}_{4}$ & 0.0800 & 0.1200 & 0.0600 & - \\
$\mathrm{iC}_{5}$ & 0.0922 & 0.1200 & 0.0600 & - \\
$\mathrm{nC}_{5}$ & 0.1000 & 0.1200 & 0.0630 & - \\
$\mathrm{C}_{6}$ & 0.0800 & 0.1200 & 0.0500 & - \\
$\mathrm{C}_{7+}-\mathrm{PN}^{b}$ & 0.0800 & 0.1000 & - & - \\
$\mathrm{C}_{7+}-\mathrm{A}^{c}$ & 0.0800 & 0.1000 & - & 0.0170
\end{tabular}

${ }^{a}$ The tabulated values are the default BIPs in PVTSim V20.0. ${ }^{b} \mathrm{PN}$ stands for paraffin and naphthene pseudo-components.

${ }^{c} \mathrm{~A}$ stands for the asphaltene pseudo-component. 
Table C.3. Experimental APE data for Oil $1 \& 2$.

\begin{tabular}{ccccc}
\hline Oil & $T(\mathrm{~K})$ & UAOP (bar) & BP (bar) & LAOP (bar) \\
\hline Oil1 & 372.15 & 472.6 & 222.1 & $\backslash$ \\
(Jamaluddin & 377.15 & 454.2 & 226.4 & $\backslash$ \\
et al., 2000) & 383.15 & 442.6 & 225.9 & $\backslash$ \\
& 389.15 & 429.2 & 226.8 & 135.1 \\
\hline \multirow{2}{*}{ Oil 2 } & 360.9 & 372.3 & 172.4 & $\backslash$ \\
(Jamaluddin & 383.2 & 279.2 & 186.2 & $\backslash$ \\
et al., 2002) & 399.8 & 251.7 & 199.9 & $\backslash$ \\
\hline
\end{tabular}

3

4

Table C.4. Parameters for Oil 1 after characterization.

\begin{tabular}{ccccccc}
\hline Component & $\begin{array}{c}Z_{i} \\
(\mathrm{~mol} \%)\end{array}$ & $\begin{array}{c}M W \\
(\mathrm{~g} / \mathrm{mol})\end{array}$ & $\begin{array}{c}T_{c} \\
(\mathrm{~K})\end{array}$ & $\begin{array}{c}P_{c} \\
(\mathrm{MPa})\end{array}$ & $\omega$ & $\begin{array}{c}C_{S} \\
\left(\mathrm{~cm}^{3} / \mathrm{mol}\right)\end{array}$ \\
\hline $\mathrm{N}_{2}$ & 0.4800 & 28.0140 & -146.9500 & 3.3944 & 0.0400 & -4.2300 \\
$\mathrm{CO}_{2}$ & 0.9200 & 44.0100 & 31.0500 & 7.3765 & 0.2250 & -1.6412 \\
$\mathrm{C}_{1}$ & 43.4300 & 16.0430 & -82.5500 & 4.6002 & 0.0080 & -5.2000 \\
$\mathrm{C}_{2}$ & 11.0200 & 30.0700 & 32.2500 & 4.8839 & 0.0980 & -5.7900 \\
$\mathrm{C}_{3}$ & 6.5500 & 44.0970 & 96.6500 & 4.2455 & 0.1520 & -6.3500 \\
$\mathrm{iC}_{4}$ & 0.7900 & 58.1240 & 134.9500 & 3.6477 & 0.1760 & -7.1800 \\
$\mathrm{nC}_{4}$ & 3.7000 & 58.1240 & 152.0500 & 3.7997 & 0.1930 & -6.4900 \\
$\mathrm{i} \mathrm{C}_{5}$ & 1.2800 & 72.1510 & 187.2500 & 3.3843 & 0.2270 & -6.2000 \\
$\mathrm{nC}_{5}$ & 2.2500 & 72.1510 & 196.4500 & 3.3741 & 0.2510 & -5.1200 \\
$\mathrm{C}_{6}$ & 2.7000 & 86.1780 & 234.2500 & 2.9688 & 0.2960 & 1.3900 \\
$\mathrm{C}_{7}$ & 2.5230 & 96.0000 & 264.9761 & 2.9902 & 0.3376 & 8.7567 \\
$\mathrm{C}_{8}$ & 2.2864 & 107.0000 & 285.5926 & 2.7590 & 0.3744 & 11.7047 \\
$\mathrm{C}_{9}$ & 2.0719 & 121.0000 & 309.3735 & 2.5165 & 0.4205 & 15.1455 \\
$\mathrm{C}_{10}-\mathrm{C}_{12}$ & 5.1209 & 146.4489 & 348.9879 & 2.2011 & 0.5020 & 20.9082 \\
$\mathrm{C}_{13}-\mathrm{C}_{14}$ & 2.6634 & 182.1310 & 396.1571 & 1.9159 & 0.6048 & 25.8329 \\
$\mathrm{C}_{15}-\mathrm{C}_{17}$ & 3.1295 & 220.6500 & 442.2934 & 1.7215 & 0.7103 & 27.4327 \\
$\mathrm{C}_{18}-\mathrm{C}_{20}$ & 2.3289 & 262.2133 & 487.3178 & 1.5853 & 0.8119 & 25.7299 \\
$\mathrm{C}_{21}-\mathrm{C}_{23}$ & 1.7331 & 303.7811 & 529.6055 & 1.4914 & 0.9025 & 21.1312 \\
$\mathrm{C}_{24}-\mathrm{C}_{27}$ & 1.6416 & 350.4955 & 574.7170 & 1.4162 & 0.9894 & 13.3732 \\
$\mathrm{C}_{28}-\mathrm{C}_{33}$ & 1.5170 & 419.0021 & 637.2527 & 1.3396 & 1.0857 & -2.0137 \\
$\mathrm{C}_{32}-\mathrm{C}_{41}$ & 1.0265 & 513.8358 & 718.6837 & 1.2717 & 1.1550 & -28.4676 \\
$\mathrm{C}_{42}-\mathrm{C}_{80}$ & 0.7511 & 707.2789 & 857.0859 & 1.1645 & 0.9549 & -85.5603 \\
$\mathrm{C}_{42}-\mathrm{C}_{80}-\mathrm{A}$ & 0.0868 & 707.2789 & 1124.9550 & 1.5511 & 1.2740 & -85.5603
\end{tabular}

Note: Oil characterization is performed using PVTSim V20.0 with 12 pseudo-components in the $\mathrm{C}_{7+}$ fraction. Asphaltene is the last pseudo-component named as ' $\mathrm{C}_{42}-\mathrm{C}_{80}-\mathrm{A}$ '. $T_{c}$ (critical temperature), $P_{c}$ (critical pressure), $\omega$ (acentric factor) and $c_{s}$ (volume shift parameter) are the required inputs for the PR-Peneloux EOS. 
Table C.5. Parameters for Oil 2 after characterization.

\begin{tabular}{ccccccc}
\hline Component & $\begin{array}{c}Z_{i} \\
(\mathrm{~mol} \%)\end{array}$ & $\begin{array}{c}M W \\
(\mathrm{~g} / \mathrm{mol})\end{array}$ & $\begin{array}{c}T_{c} \\
(\mathrm{~K})\end{array}$ & $\begin{array}{c}P_{c} \\
(\mathrm{MPa})\end{array}$ & $\omega$ & $\begin{array}{c}C_{S} \\
\left(\mathrm{~cm}^{3} / \mathrm{mol}\right)\end{array}$ \\
\hline $\mathrm{N}_{2}$ & 0.4900 & 28.0135 & -146.9500 & 3.3944 & 0.0400 & -4.2300 \\
$\mathrm{CO}_{2}$ & 11.3689 & 44.0098 & 31.0500 & 7.3765 & 0.2250 & -1.6412 \\
$\mathrm{H}_{2} \mathrm{~S}$ & 3.2197 & 34.0800 & 100.0500 & 8.9369 & 0.1000 & -3.8400 \\
$\mathrm{C}_{1}$ & 27.3573 & 16.0429 & -82.5500 & 4.6002 & 0.0080 & -5.2000 \\
$\mathrm{C}_{2}$ & 9.4091 & 30.0698 & 32.2500 & 4.8839 & 0.0980 & -5.7900 \\
$\mathrm{C}_{3}$ & 6.6993 & 44.0968 & 96.6500 & 4.2455 & 0.1520 & -6.3500 \\
$\mathrm{iC}_{4}$ & 0.8099 & 58.1237 & 134.9500 & 3.6477 & 0.1760 & -7.1800 \\
$\mathrm{nC}_{4}$ & 3.1697 & 58.1237 & 152.0500 & 3.7997 & 0.1930 & -6.4900 \\
$\mathrm{iC}_{5}$ & 1.2199 & 72.1506 & 187.2500 & 3.3843 & 0.2270 & -6.2000 \\
$\mathrm{nC}_{5}$ & 1.9798 & 72.1506 & 196.4500 & 3.3741 & 0.2510 & -5.1200 \\
$\mathrm{C}_{6}$ & 2.4898 & 86.1780 & 234.2500 & 2.9688 & 0.2960 & 1.3900 \\
$\mathrm{C}_{7}$ & 2.6141 & 96.0000 & 265.6546 & 3.0087 & 0.3377 & 9.5617 \\
$\mathrm{C}_{8}$ & 2.3995 & 107.0000 & 286.2025 & 2.7741 & 0.3744 & 12.4725 \\
$\mathrm{C}_{9}$ & 2.2025 & 121.0000 & 309.9230 & 2.5288 & 0.4206 & 15.8939 \\
$\mathrm{C}_{10}-\mathrm{C}_{12}$ & 5.5808 & 146.5638 & 349.6007 & 2.2085 & 0.5024 & 21.6171 \\
$\mathrm{C}_{13}-\mathrm{C}_{15}$ & 4.3161 & 189.4497 & 406.0221 & 1.8775 & 0.6266 & 27.1015 \\
$\mathrm{C}_{16}-\mathrm{C}_{18}$ & 3.3380 & 235.8392 & 459.3572 & 1.6679 & 0.7487 & 27.6153 \\
$\mathrm{C}_{19}-\mathrm{C}_{22}$ & 3.3049 & 281.9846 & 508.3033 & 1.5386 & 0.8571 & 24.3764 \\
$\mathrm{C}_{23}-\mathrm{C}_{25}$ & 1.8327 & 330.5637 & 555.6526 & 1.4459 & 0.9542 & 17.0954 \\
$\mathrm{C}_{26}-\mathrm{C}_{30}$ & 2.1790 & 385.3735 & 606.9862 & 1.3729 & 1.0432 & 5.9138 \\
$\mathrm{C}_{31}-\mathrm{C}_{36}$ & 1.6379 & 461.5180 & 673.9462 & 1.3039 & 1.1266 & -13.9056 \\
$\mathrm{C}_{37}-\mathrm{C}_{46}$ & 1.4027 & 567.2266 & 762.8154 & 1.2428 & 1.1591 & -46.0391 \\
$\mathrm{C}_{47}-\mathrm{C}_{80}$ & 0.8099 & 783.1848 & 910.4160 & 1.1075 & 0.7903 & -115.9724 \\
$\mathrm{C}_{47}-\mathrm{C}_{80}-\mathrm{A}$ & 0.1690 & 783.1848 & 1084.7670 & 1.6114 & 1.2740 & -115.9724 \\
\hline & & & & & &
\end{tabular}

Table C.6. Experimental APE data for Oil 3 (Zhang et al., 2012).

\begin{tabular}{ccc}
\hline & $T(\mathrm{~K})$ & $P($ bar $)$ \\
\hline \multirow{4}{*}{ UAOP } & 321.58 & 623.16 \\
& 338.46 & 583.67 \\
& 354.97 & 511.99 \\
& 371.66 & 468.10 \\
& 389.11 & 432.99 \\
& 424.59 & 400.81 \\
\hline \multirow{2}{*}{ BP } & 282.12 & 143.36 \\
& 321.96 & 182.85 \\
& 338.84 & 194.56 \\
& 355.35 & 207.72 \\
\multirow{2}{*}{ LAOP } & 371.85 & 215.03 \\
& 389.49 & 223.81 \\
\hline
\end{tabular}


Table C.7. Parameters for Oil 3 after characterization.

\begin{tabular}{ccccccc}
\hline Component & $\begin{array}{c}Z_{i} \\
(\mathrm{~mol} \%)\end{array}$ & $\begin{array}{c}M W \\
(\mathrm{~g} / \mathrm{mol})\end{array}$ & $\begin{array}{c}T_{c} \\
(\mathrm{~K})\end{array}$ & $\begin{array}{c}P_{c} \\
(\mathrm{MPa})\end{array}$ & $\omega$ & $\begin{array}{c}C_{S} \\
\left(\mathrm{~cm}^{3} / \mathrm{mol}\right)\end{array}$ \\
\hline $\mathrm{N}_{2}$ & 0.0880 & 28.0140 & 126.2000 & 3.3944 & 0.0400 & -4.2300 \\
$\mathrm{CO}_{2}$ & 0.0480 & 44.0100 & 304.2000 & 7.3765 & 0.2250 & -1.6412 \\
$\mathrm{H}_{2} \mathrm{~S}$ & 1.0220 & 34.0800 & 373.2000 & 8.9369 & 0.1000 & -3.8400 \\
$\mathrm{C}_{1}$ & 42.4200 & 16.0430 & 190.6000 & 4.6002 & 0.0080 & -5.2000 \\
$\mathrm{C}_{2}$ & 10.8000 & 30.0700 & 305.4000 & 4.8839 & 0.0980 & -5.7900 \\
$\mathrm{C}_{3}$ & 6.9180 & 44.0970 & 369.8000 & 4.2455 & 0.1520 & -6.3500 \\
$\mathrm{iC}_{4}$ & 0.9570 & 58.1240 & 408.1000 & 3.6477 & 0.1760 & -7.1800 \\
$\mathrm{nC}_{4}$ & 3.5180 & 58.1240 & 425.2000 & 3.7997 & 0.1930 & -6.4900 \\
$\mathrm{iC}_{5}$ & 1.2130 & 72.1510 & 460.4000 & 3.3843 & 0.2270 & -6.2000 \\
$\mathrm{nC}_{5}$ & 2.0860 & 72.1510 & 469.6000 & 3.3741 & 0.2510 & -5.1200 \\
$\mathrm{C}_{6}$ & 2.8600 & 86.1780 & 507.4000 & 2.9688 & 0.2960 & 1.3900 \\
$\mathrm{C}_{7}$ & 2.8628 & 96.0000 & 536.5785 & 2.9477 & 0.3375 & 6.8219 \\
$\mathrm{C}_{8}$ & 2.5710 & 107.0000 & 557.2214 & 2.7210 & 0.3742 & 9.6927 \\
$\mathrm{C}_{9}$ & 2.3088 & 121.0000 & 581.0256 & 2.4828 & 0.4203 & 13.0073 \\
$\mathrm{C}_{10}-\mathrm{C}_{12}$ & 5.6077 & 146.3680 & 620.5629 & 2.1737 & 0.5015 & 18.5535 \\
$\mathrm{C}_{13}-\mathrm{C}_{14}$ & 2.8503 & 182.0971 & 667.8469 & 1.8928 & 0.6045 & 23.1811 \\
$\mathrm{C}_{15}-\mathrm{C}_{16}$ & 2.2988 & 213.5703 & 705.5964 & 1.7303 & 0.6907 & 24.3658 \\
$\mathrm{C}_{17}-\mathrm{C}_{19}$ & 2.6417 & 249.4019 & 745.5498 & 1.6028 & 0.7816 & 23.2618 \\
$\mathrm{C}_{20}-\mathrm{C}_{22}$ & 1.9133 & 289.2588 & 787.0623 & 1.5042 & 0.8722 & 19.5174 \\
$\mathrm{C}_{23}-\mathrm{C}_{25}$ & 1.3857 & 330.3681 & 827.2635 & 1.4303 & 0.9537 & 13.0428 \\
$\mathrm{C}_{26}-\mathrm{C}_{30}$ & 1.5137 & 384.7589 & 878.3334 & 1.3599 & 1.0422 & 1.7447 \\
$\mathrm{C}_{31}-\mathrm{C}_{39}$ & 1.3183 & 476.1187 & 959.4429 & 1.2825 & 1.1351 & -22.2064 \\
$\mathrm{C}_{40}-\mathrm{C}_{80}$ & 0.7457 & 672.2468 & 1103.4520 & 1.1821 & 1.0149 & -80.0383 \\
$\mathrm{C}_{40}-\mathrm{C}_{80}-\mathrm{A}$ & 0.0521 & 672.2468 & 1504.9710 & 1.4361 & 1.2740 & -80.0383 \\
\hline & & & & & &
\end{tabular}

